Article

\title{
Residue Cost Formation of a High Bypass Turbofan Engine
}

\author{
Lugo-Méndez Helen ${ }^{1}{ }^{(0}$, Castro-Hernández Sergio ${ }^{2}{ }^{\circledR}$, Salazar-Pereyra Martín ${ }^{3}{ }^{\mathbb{D}}$, \\ Valencia-López Javier ${ }^{1}\left(\mathbb{D}\right.$, Torres-González Edgar Vicente ${ }^{2}\left(\mathbb{C}\right.$ and Lugo-Leyte Raúl ${ }^{2, * \mathbb{C}}$ \\ 1 Departamento de Procesos y Tecnología, Universidad Autónoma Metropolitana-Cuajimalpa, \\ Av. Vasco de Quiroga 4871, Santa Fé, Cuajimalpa, Ciudad de México 05348, Mexico; \\ hlugo@cua.uam.mx (L.-M.H.); jvalencia@cua.uam.mx (V.-L.J.) \\ 2 Departamento de Ingeniería de Procesos e Hidráulica, Universidad Autónoma Metropolitana-Iztapalapa, \\ Av. San Rafael Atlixco 186, Vicentina, Iztapalapa, Ciudad de México 09340, Mexico; \\ sch@xanum.uam.mx (C.-H.S.); etorres@xanum.uam.mx (T.-G.E.V.) \\ 3 División de Ingeniería Mecatrónica e Industrial, Tecnológico de Estudios Superiores de Ecatepec, \\ Av. Tecnológico Esq. Av. Hank González, Valle de Anáhuac, Ecatepec 55210, Mexico; msalazar@tese.edu.mx \\ * Correspondence: lulr@xanum.uam.mx; Tel.: +52-555-804-4600 (ext. 1156)
}

Received: 26 November 2020; Accepted: 14 December 2020; Published: 18 December 2020

\begin{abstract}
The kinetic energy produced by a turbofan engine is inseparable from the unavoidable generation of waste heat dissipated into the environment and the chemical exergy of exhaust gases. However, exergoeconomic cost analyses of these propulsion systems have focused only on the formation process of the functional product and not the cost of residue formation. In this study, symbolic thermoeconomics was applied to evaluate the impact of residue formation on the production costs of a turbofan engine and analyze the effect of component malfunctions on the fuel impact formula for diagnosing anomalies. The GE90-115B high bypass turbofan engine under takeoff conditions and a thrust requirement of $510 \mathrm{kN}$ was considered as a case study. The total exergoeconomic cost of the engine was $26,754.28 \mathrm{USD} / \mathrm{h}: 61.04 \%$ corresponded to external resources; $0.14 \%$ and $33.07 \%$ corresponded to waste heat dissipated from the bypass and core engine, respectively; $3.28 \%$ corresponded to the chemical exergy of the exhaust gases; $2.47 \%$ corresponded to capital and operating costs. A malfunction analysis revealed that a $1 \%$ reduction in the isentropic efficiency of the compressor reduced the total kinetic exergy by $-0.77 \mathrm{MW}$, increased fuel consumption by $0.49 \mathrm{MW}$, and generated irreversibility and residue of 0.80 and $0.45 \mathrm{MW}$, respectively.
\end{abstract}

Keywords: exergoeconomic cost analysis; cost formation of residues; malfunctions; turbofan

\section{Introduction}

The aviation sector contributes significantly to economic growth and an increasingly globalized society [1], but at a cost of $2-3 \%$ of total fossil fuel consumption and $2 \%$ of total greenhouse gas emissions worldwide [2]. In this sector, major priorities are not only to operate with the maximum cost effectiveness, but also to reduce fuel consumption and emissions of greenhouse gases and pollutants. Several studies have been conducted in which energy, exergy, and exergoeconomic analyses were applied to aviation propulsion systems as important tools for understanding and optimizing their operation to identify operational, economic, and environmental improvement opportunities [1,3-8]. In these studies, the most frequently used method was specific exergy costing, which is based on algebraic cost balance equations obtained from conventional economic analyses and complemented with auxiliary equations [9]. However, these studies have been conducted with a focus only on the formation of the functional product of aircraft engines (i.e., kinetic exergy) without considering the 
unavoidable formation of residues (i.e., waste heat dissipated from the engine and the chemical exergy of combustion gases). For these energy systems, residues are considered an exergy loss because they cannot be reused and they contribute to environmental pollution.

Thermoeconomics is a powerful analytical tool for cost accounting that is based on exergy cost theory (ECT), which combines the second law of thermodynamics and economics [10]. It provides a rationale for assessing the production cost of energy systems in terms of the consumption of natural resources and their impact on the environment, money, and system irreversibilities [11]. Thermoeconomics can be used to help design, diagnose, and optimize complex energy systems. More precisely, it can help to determine how energy and resources degrade, identify which systems work better, improve the design to reduce consumption, and prevent residues from damaging the environment [12]. Exergy cost theory offers a procedure for determining the production costs of productive components of a system. This theory has been extended to dissipative components, but does not present a general procedure for identifying residue formation costs and their effect on the production costs [10]. The best residue distribution criteria among possible alternatives are still an open question [13-16]. Valero et al. proposed an exergoeconomic methodology known as symbolic thermoeconomics to determine the process cost of functional products and residues and establish a mathematical basis for the production cost assessment. It develops a productive scheme (i.e., productive structure) of the exergy flow distribution throughout the system and its interaction with the environment, which are obtained from its physical structure [10,17]. This methodology formulates two alternative representations for the productive structure of a system: fuel-product-residue (FPR) and product-fuel-residue (PFR). These respectively use the external resources and plant product of the system as known information. Both approaches lead to the same results in terms of costs. The FPR representation is mainly adopted for cost accounting, whereas the PFR representation is highly useful for thermoeconomic diagnosis [18]. Thermoeconomic diagnosis is focused on identifying and interpreting anomalously functioning components and evaluating the effect of each component on additional fuel consumption. Symbolic thermoeconomics also includes the identification of malfunctions and dysfunctions to account for the impact of anomalies on fuel consumption [19,20].

The main motivation of this study is to address the lack of exergoeconomic analysis on the contribution of residue formation to the production cost of turbofan engines. This paper is organized into six different sections. In Section 2, a brief description of a turbofan is presented. Section 3 contains the model, derived from the energy balances of the turbofan and its components, to predict the thermodynamics states of the aircraft engine. Section 4 presents the turbofan productive structure, the exergy balance equations of its components, and the fuel-product-residue table. Section 5 exposes a summary of the mathematical basis for the cost assessment and the formation process of residues. Section 6 presents a summary of thermoeconomic diagnosis theory based on the malfunction and dysfunction analysis. Section 7 deals with the application of the aforementioned methodologies to a GE90-115B aircraft engine at takeoff condition and a thrust requirement of $510 \mathrm{kN}$, and the malfunction analysis is performed to quantify the effects of a decrease in compressor efficiency (malfunction) in the other components of the i engine. Finally, the main contributions of the paper and the discussions on the results are summarized in Section 8.

\section{System Description}

\subsection{General Description of the Engine Operation}

Turbofan engines with a high bypass ratio are used in considerably large commercial and military transport aircraft. Particularly in modern aircraft, this part of the engine generates $75-80 \%$ of the total thrust.

Figure 1 shows a schematic of a turbofan engine. From far upstream, where the air velocity relative to the engine is given by the flight velocity $(w)$, the air is brought to the diffuser (D), which decreases its velocity in the flow direction. The air mass flow rate $\left(\dot{m}_{a}\right)$ is carried to the fan $(\mathrm{F})$; a fraction of the 
air is moved to the bypass nozzle (FN), and the remainder moves to the core engine $\left(\dot{m}_{a}=\dot{m}_{c a}+\dot{m}_{h a}\right)$. The relation between air flowing through the FN $\left(\dot{m}_{c a}\right)$ and gas turbine $\left(\dot{m}_{h a}\right)$ is called the bypass ratio: $\beta=\dot{m}_{c a} / \dot{m}_{h a}$. The fraction of the air mass flow rate $\dot{m}_{c a}=\beta \dot{m}_{a} /(1+\beta)$ is accelerated in the FN and exhausted to the environment, whereas the remaining fraction $\left(\dot{m}_{h a}=\dot{m}_{a} /(1+\beta)\right)$ enters the compressor (C) of the two-shaft gas turbine. In the combustion chamber (CC), the compressed air is heated $\left(\dot{Q}_{b}\right)$ by mixing and combustion with the atomized aviation fuel Jet-A1 (kerosene). The combustion reaction between this fuel and air, which is assumed to have a molar composition of $79 \% \mathrm{~N}_{2}$ and $21 \% \mathrm{O}_{2}$, is given by:

$$
\begin{aligned}
\mathrm{C}_{n} \mathrm{H}_{m}+\left(n+\frac{m}{4}\right)(1+\lambda) & \left(\mathrm{O}_{2}+3.76 \mathrm{~N}_{2}\right) \rightarrow\left[n\left(1-k_{4}\right)-k_{1}\right] \mathrm{CO}_{2} \\
+ & \frac{m}{2}\left(1-k_{4}\right) \mathrm{H}_{2} \mathrm{O}+\left[3.76\left(n+\frac{m}{4}\right)(1+\lambda)-\frac{k_{2}+k_{3}}{2}\right] \mathrm{N}_{2} \\
+ & {\left[\left(n+\frac{m}{4}\right)(1+\lambda)+\frac{k_{1}-k_{2}}{2}-k_{3}\right] \mathrm{O}_{2}+k_{1} \mathrm{CO}+k_{2} \mathrm{NO}+k_{3} \mathrm{NO}_{2}+k_{4} \mathrm{C}_{n} \mathrm{H}_{m} }
\end{aligned}
$$

where $n$ and $m$ are the numbers of $\mathrm{C}$ and $\mathrm{H}$ atoms present in the fuel, $\lambda$ is the excess of air, and $k_{1}$ to $k_{4}$ are the stoichiometric coefficients for $\mathrm{CO}, \mathrm{NO}, \mathrm{NO}_{2}$, and $\mathrm{C}_{n} \mathrm{H}_{m}$, respectively. This reaction determines the chemical composition of the combustion gases. The mass flow rate $\dot{m}_{c g}=\dot{m}_{h a}+\dot{m}_{f}$ and $\dot{m}_{f}$ is the fuel mass flow rate. The combustion gases leave the CC at a substantially high pressure and temperature and are expanded in the high pressure turbine (HPT) and low pressure turbine (LPT) to generate useful work for driving the $\mathrm{C}$ and F, respectively. The exhaust gases exiting the LPT are accelerated and expelled through the exhaust nozzle $(\mathrm{N})$ at considerably high speeds.

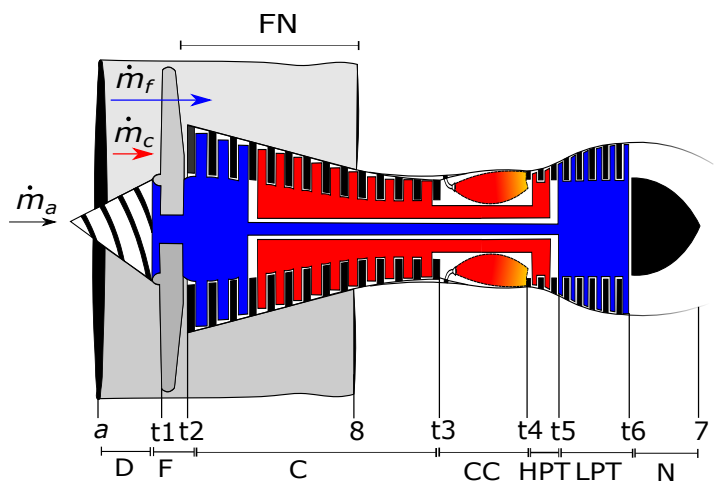

Figure 1. Schematic diagram of a turbofan engine.

\subsection{Assumptions}

In this study, the following assumptions were made.

- The engine operates in a steady state with a steady flow.

- Air and combustion gases behave as mixtures of ideal gases and one-dimensional and adiabatic steady flows.

- The chemical formula of JET-A1 is $\mathrm{C}_{12} \mathrm{H}_{23}$, and its lower heating value (LHV) is $42,800 \mathrm{~kJ} / \mathrm{kg}$ [21].

- The changes in potential energy within the engine are negligible.

- The cooling air mass flow is not considered for analysis [22].

- The heat exchangers (air-fuel, fuel-oil) are not considered.

- The temperature and pressure in the dead state are $288.15 \mathrm{~K}$ and $101.33 \mathrm{kPa}$, respectively.

\section{Energy Analysis}

The energy balances of the turbofan components are presented in Table $1 . \dot{H}_{t}$ is the stagnation enthalpy flow, which is the sum of the flow rates for the static enthalpy $(\dot{H})$ and kinetic energy $\left(m u^{2} / 2\right)$. 
Table 1. Energy balance and adiabatic efficiency of the turbofan components.

\begin{tabular}{|c|c|c|}
\hline Component & Energy Balance & Adiabatic Efficiency \\
\hline $\mathrm{D}$ & $\dot{H}_{t 1}-\dot{H}_{a}=\frac{1}{2} \dot{m}_{a} u_{a}^{2}$ & $\eta_{D}=\frac{h_{t 1 s}-h_{a}}{h_{t 1}-h_{a}}$ \\
\hline $\mathrm{F}$ & $\dot{W}_{F}=\dot{H}_{t 2}-\dot{H}_{t 1}$ & $\eta_{F}=\frac{h_{t 2 s}-h_{t 1}}{h_{t 2}-h_{t 1}}$ \\
\hline $\mathrm{C}$ & $\dot{W}_{C}=\dot{H}_{t 3}-\dot{H}_{t 2}$ & $\eta_{C}=\frac{h_{t 3 s}-h_{t 2}}{h_{t 3}-h_{t 2}}$ \\
\hline $\mathrm{CC}$ & $\dot{Q}_{b}=\dot{H}_{t 4}-\dot{H}_{t 3}$ & $\eta_{b}=\frac{q_{b}}{L H V}$ \\
\hline $\mathrm{HPT}$ & $\dot{W}_{H P T}=\dot{H}_{t 4}-\dot{H}_{t 5}=\dot{W}_{C}$ & $\eta_{H P T}=\frac{n_{t 4}-n_{t 5}}{h_{t 4}-h_{t 5 s}}$ \\
\hline LPT & $\dot{W}_{L P T}=\dot{H}_{t 5}-\dot{H}_{t 6}=\dot{W}_{F}$ & $\eta_{L P T}=\frac{h_{t 5}-h_{t 6}}{h_{t 5}-h_{t t 6}}$ \\
\hline FN & $\frac{\beta \dot{H}_{t 2}-(1+\beta) \dot{H}_{8}}{1+\beta}=\frac{\beta \dot{m}_{a}}{2(1+\beta)} u_{8}^{2}$ & $\eta_{F N}=\frac{h_{t 2}-h_{8}}{h_{t 2}-h_{t 8 s}}$ \\
\hline $\mathrm{N}$ & $\dot{H}_{t 6}-\dot{H}_{7}=\frac{1}{2} \dot{m}_{c g} u_{7}^{2}$ & $\eta_{N}=\frac{h_{t 6}-h_{7}}{h_{t 6}-h_{t 7 s}}$ \\
\hline Turbofan & $\dot{H}_{t a}+\dot{Q}_{b}=\dot{H}_{t 7}+\dot{H}_{t 8}$ & \\
\hline
\end{tabular}

The fuel-to-air ratio ( far) is obtained from the energy balance for the CC (Table 1) and is expressed as:

$$
f a r=\frac{\dot{m}_{f}}{\dot{m}_{a}}=\left(\frac{1}{\beta+1}\right) \frac{h_{t 4}-h_{t 3}}{\eta_{b} L H V-h_{t 4}}
$$

where $h_{t 4}$ and $h_{t 3}$ are the stagnation enthalpies of air and combustion gases in States 3 and 4 , respectively, and $\eta_{b}$ is the adiabatic efficiency of the CC.

Table 2 lists the temperatures and pressures of each state, as derived from the energy balance. $T_{t}$ and $P_{t}$ are the stagnation temperature and pressure, respectively.

If the nozzles are not choked, then the pressure at the exit of each nozzle is equal to the specified back pressure $\left(P_{7}=P_{a}=P_{8}\right)$, as shown in Table 2 . The resulting velocities are expressed as follows.

$$
\left.u_{7}=\sqrt{\frac{2 \gamma_{c g}}{\gamma_{c g}-1} R_{c g} T_{t 6} \eta_{N}\left[1-\left(\frac{P_{a}}{P_{t 6}}\right)^{\frac{\gamma_{c g}}{\gamma_{c g}-1}}\right]} \text { and } u_{8}=\sqrt{\frac{2 \gamma_{a}}{\gamma_{a}-1} R_{a} T_{t 2} \eta_{F N}\left[1-\left(\frac{P_{a}}{P_{t 2}}\right)^{\frac{\gamma_{a}}{\gamma_{a}-1}}\right.}\right]
$$

In this study, the thrust is the net force acting on the $x$-surface of the control volume in the $x$-direction. If the density is constant at the entrance and exit surfaces, the exhaust plane pressure is atmospheric and $u_{a}=M \sqrt{\gamma_{a} R_{a} T_{a}}$. The thrust per unit airflow is then given as:

$$
\frac{\tau}{\dot{m}_{a}}=\frac{[1+(1+\beta) \text { far }] u_{7}-u_{a}+\beta\left(u_{8}-u_{a}\right)}{1+\beta}
$$

The energy balance of the turbofan presented in Table 1 can be expressed as:

$$
\dot{Q}_{b}=\underbrace{\frac{[1+(1+\beta) f a r] u_{7}^{2}-u_{a}^{2}+\beta\left(u_{8}^{2}-u_{a}^{2}\right)}{1+\beta} \dot{m}_{a}}_{\text {Propulsive kinetic energy (useful energy) }}+\underbrace{\frac{[1+(1+\beta) f a r] h_{7}-h_{a}+\beta\left(h_{7}-h_{a}\right)}{1+\beta} \dot{m}_{a}}_{\text {Thermal energy (unuseful energy) }}
$$

The energy performance indicators are the thermal efficiency, propulsion efficiency, and overall efficiency. According to Equation (5), the thermal efficiency $\eta_{t h}$ is the relation between the propulsive 
kinetic energy and total heat input $\dot{Q}_{b}$. The propulsion efficiency $\eta_{\text {prop }}$ relates the thrust power $\dot{\tau}=\tau u_{a}$ required by the turbofan to the propulsive kinetic energy. The overall efficiency $\eta_{\text {overall }}$ is the ratio of the thrust power to the total heat input $\eta_{\text {overall }}=\eta_{\text {th }} \eta_{\text {prop }}$.

Table 2. Thermodynamic states of the turbofan engine.

\begin{tabular}{cccc}
\hline State & $\begin{array}{c}\text { Mass } \\
\text { Flow Rate }\end{array}$ & Temperature & Pressure \\
\hline$a$ & $\dot{m}_{a}$ & $T_{a}$ & $P_{a}$ \\
$0 a$ & $\dot{m}_{a}$ & $\frac{T_{t a}}{T_{a}}=1+\frac{\gamma_{a}-1}{2} M^{2}$ & $\frac{P_{t a}}{P_{a}}=\left(1+\frac{\gamma_{a}-1}{2} M^{2}\right)^{\frac{\gamma_{a}}{\gamma_{a}-1}}$ \\
01 & $\dot{m}_{a}$ & $\frac{P_{t 1}}{P_{a}}=\left(1+\eta_{D} \frac{\gamma_{a}-1}{2} M^{2}\right)^{\frac{\gamma_{a}}{\gamma_{a}-1}}$ \\
02 & $\dot{m}_{a}$ & $\frac{T_{t 2}}{T_{a}}=1+\frac{1}{\eta_{F}}\left(\pi_{F}^{\frac{\gamma_{a-1}}{\gamma_{a}}}-1\right)$ & $\frac{P_{t 2}}{P_{t 1}}=\pi_{F}$ \\
03 & $\frac{\dot{m}_{a}}{1+\beta}$ & $\frac{T_{t 3}}{T_{t 2}}=1+\frac{1}{\eta_{C}}\left(\pi_{C}^{\frac{\gamma_{a}-1}{\gamma_{a}}}-1\right)$ & $\frac{P_{t 3}}{P_{t 2}}=\pi_{C}$ \\
04 & $\dot{m}_{c g}$ & $\frac{P_{t 4}}{P_{t 3}}=1-\Delta P_{b}$ \\
05 & $\dot{m}_{c g}$ & $T_{t 5}=T_{t 4}-\frac{T_{t 3}-T_{t 2}}{1+(1+\beta) f a r}$ & $\frac{P_{t 5}}{P_{t 4}}=\left[1-\frac{1}{\eta_{H P T}}\left(1-\frac{T_{t 5}}{T_{t 4}}\right)\right]^{\frac{\gamma_{c g}}{\gamma_{c g}-1}}$ \\
06 & $\dot{m}_{c g}$ & $T_{t 6}=T_{t 4}-\frac{(1+\beta)\left(T_{t 2}-T_{t 1}\right)}{1+(1+\beta) f a r}$ & $\frac{P_{t 6}}{P_{t 5}}=\left[1-\frac{1}{\eta_{L P T}}\left(1-\frac{T_{t 6}}{T_{t 5}}\right)\right]^{\gamma_{c g}-1}$ \\
7 & $\dot{m}_{c g}$ & $\frac{T_{7}}{T_{t 6}}=1-\eta_{N}\left[1-\left(\frac{P_{a}}{P_{t 6}}\right)^{\frac{\gamma_{c g}}{\gamma_{c g}-1}}\right]$ & $P_{7}=P_{a}$ \\
8 & $\frac{\beta \dot{m}_{a}}{1+\beta}$ & $\frac{T_{8}}{T_{t 2}}=1-\eta_{F N}\left[1-\left(\frac{P_{a}}{P_{t 2}}\right)\right.$ & $\left.\frac{\gamma_{a}}{\gamma_{a}-1}\right]$ \\
$P_{8}=P_{a}$ \\
\hline
\end{tabular}

\section{Exergy Analysis}

\subsection{Exergy Forms}

Exergy is defined as the maximum useful work that can be produced by a system interacting with a specified reference environment (known as the dead state and denoted by a zero subscript). In the absence of influences such as nuclear effects, magnetism, electricity, and surface tension, the exergy of a stream of a substance comprises its kinetic $\left(\dot{E}^{K}\right)$, potential $\left(\dot{E}^{P}\right)$, physical $\left(\dot{E}^{P H}\right)$, and chemical $\left(\dot{E}^{\mathrm{CH}}\right)$ exergies.

$$
\dot{E}_{t}=\dot{E}^{K}+\dot{E}^{P}+\dot{E}^{P H}+\dot{E}^{C H}
$$

The kinetic exergy is equal to the kinetic energy when the velocity is considered relative to the surface of the Earth, and the potential exergy is equal to the potential energy when considered with respect to the average surface level of the Earth in the environment of the process under consideration [23].

$$
\dot{E}^{K}=\frac{\dot{m} u^{2}}{2} \text { and } \dot{E}^{P}=\dot{m} g z
$$

where $u$ and $z$ are respectively the velocity and elevation relative to coordinates of the environment and $g$ is the gravity. 
The physical exergy is the maximum work obtainable by taking the substance through reversible physical processes from its initial state to the state determined by $T_{0}$ and $P_{0}$ [23]. It is defined as $d E^{P H}=d H-T_{0}(d H / T-V / T d P)$ and for a mixture of ideal gases yields:

$$
\dot{E}^{P H}=\dot{m}\left[c_{P m}\left(T-T_{0}-T_{0} \ln \frac{T}{T_{0}}\right)+R_{m} T_{0} \ln \frac{P}{P_{0}}\right]
$$

where $c_{P m}$ is the heat capacity at a constant pressure and $R_{m}$ is the specific gas constant of the mixture. The chemical exergy is the work that can be obtained by taking a substance at $T_{0}$ and $P_{0}$ to chemical equilibrium with the environment [23]. The molar chemical exergy of a mixture of ideal gases can be determined from the knowledge of the standard molar chemical exergies $\left(\varepsilon_{0, i}^{\mathrm{CH}}\right)$ and molar compositions $\left(x_{i}\right)$ of the species in the mixture: [24].

$$
{ }_{\varepsilon}^{\mathrm{CH}}=\sum x_{i} \varepsilon_{0, i}^{\mathrm{CH}}+R_{u} T_{0} \sum x_{i} \ln x_{i}
$$

For a unit mass, the specific chemical exergy of a liquid fuel is determined from the fuel exergy grade function [3].

$$
\xi=\frac{e_{f}^{C H}}{L H V}=1.0401+0.01728 \frac{\mathrm{H}}{\mathrm{C}}+0.0432 \frac{\mathrm{O}}{\mathrm{C}}+0.2196 \frac{\mathrm{S}}{\mathrm{C}}\left(1+2.0628 \frac{\mathrm{H}}{\mathrm{C}}\right)
$$

where $\mathrm{H}, \mathrm{C}, \mathrm{O}$, and $\mathrm{S}$ are the mass fractions of their respective elements. Sulfur is neglected for kerosene fuel [25]; thus, the exergy flow rate of jet fuel is given as:

$$
\dot{E}_{f}=\dot{m}_{f} e_{f}^{C H}=\dot{m}_{f} \xi L H V
$$

The exergy of a system can be increased or decreased by the transfer of exergy corresponding to either work or heat. The exergy of mechanical work $\left(\dot{E}_{\dot{W}}\right)$ is identical to that of mechanical work $(\dot{W})$ :

$$
\dot{E}_{\dot{W}}=\dot{W}
$$

The exergy associated with combustion heat transfer $\left(\dot{Q}_{b}=\dot{m}_{f} \eta_{b} L H V=\eta_{b} \dot{E}_{f} / \xi\right)$ at temperature $T_{t 4}$ is:

$$
\dot{E}_{\dot{Q}_{b}}=\dot{Q}_{b}\left(1-\frac{T_{0}}{T_{t 4}}\right)
$$

The exergies associated with the heat transfer from the exhausted combustion gases $\left(\dot{E}_{\dot{Q}_{h}}\right)$ and air $\left(\dot{E}_{\dot{Q}_{c}}\right)$ into the environment at $T_{7}$ and $T_{8}$, respectively, can be approximated by neglecting the irreversibility within the fluid and assuming the specific heat capacity to be constant [26].

$$
\dot{E}_{\dot{Q}_{h}}=\dot{Q}_{h}\left(1-\frac{T_{0}}{T_{7}-T_{0}} \ln \frac{T_{7}}{T_{0}}\right) \text { and } \dot{E}_{\dot{Q}_{c}}=\dot{Q}_{c}\left(1-\frac{T_{0}}{T_{8}-T_{0}} \ln \frac{T_{8}}{T_{0}}\right)
$$

where $\dot{Q}_{h}=\dot{H}_{7}$ and $\dot{Q}_{c}=\dot{H}_{8}$ are the transferred heat from the exhaust gases and air into the environment.

\subsection{Productive Structure}

A productive structure is a graphical representation of the costs for the formations of the product and residues. It explains the distribution of resources and internal products throughout an energy system by using a physical model as a reference [13]. The products of each component fuel other 
components to form the main product, byproducts, or residues [27]. As shown in Figure 2, the external resources of the turbofan engine are the total exergy of air and aviation fuel. The products are the kinetic exergy of air and combustion gases in States 7 and 8, which provide the thrust to sustain flight. The residual exergy streams are the chemical exergy of the exhaust gases and the physical exergy of the air and combustion gases leaving their respective nozzles.The products and residues of an energy system are formed within their productive components, and the residues are released to the environment through dissipative components. The productive components provide resources to other components to form the final products and residual streams of an energy system. The set of the productive components of a turbofan engine is $\mathscr{P}=\{\mathrm{D}, \mathrm{F}, \mathrm{FN}, \mathrm{C}, \mathrm{CC}, \mathrm{HPT}, \mathrm{LPT}, \mathrm{N}\}$.

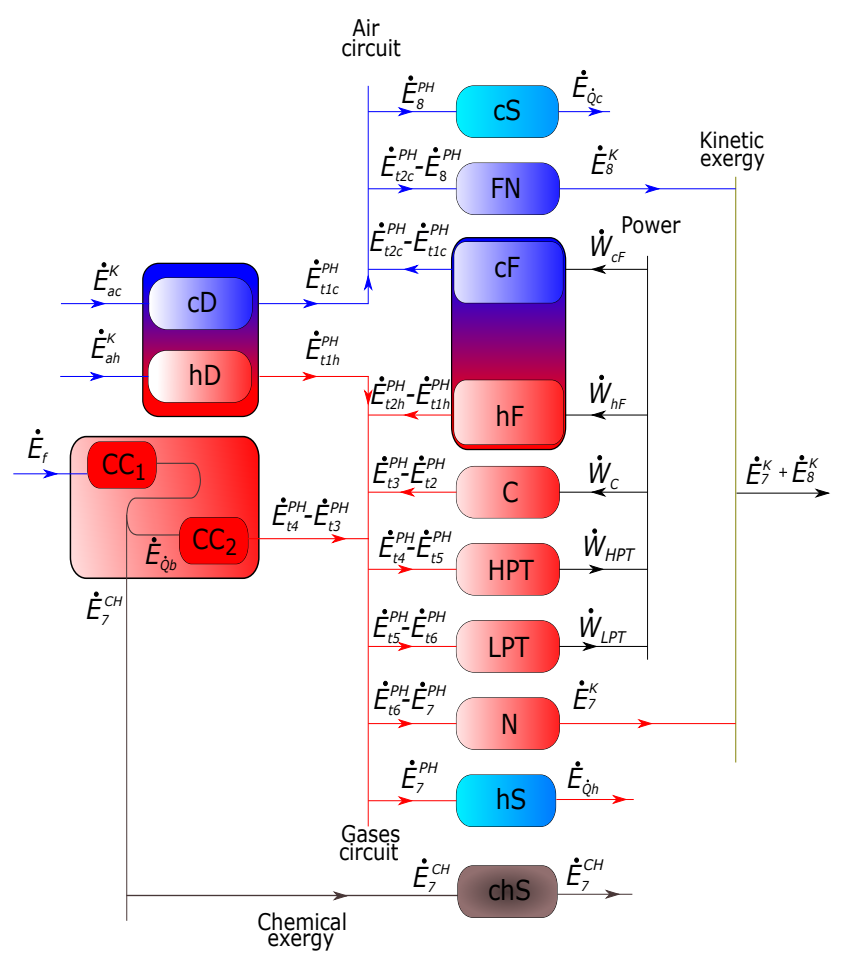

Figure 2. Productive structure of a turbofan engine. hS, hot stack.

The state at the entrance of the $\mathrm{D}$ (state $a$ ) corresponds to the dead state. Therefore, the total air exergy flow is equal to its kinetic exergy $\left(\dot{E}_{a}=\dot{E}_{a}^{K}\right)$. In the D, the air kinetic energy is converted into pressure energy, and the air reaches the stagnation state 01 . The productive objective of the $\mathrm{F}$ and $\mathrm{C}$ is to increase the physical exergy of the air $\left(\dot{m}_{a}\right.$ and $\left.\dot{m}_{h}\right)$ by increasing the air pressure using the fan and compression power, respectively, as resources. In the CC, the exothermic reaction between air and fuel is used to convert the chemical exergy of JET-A1 into the exergy associated with the combustion heat $\left(\dot{E}_{\dot{Q}_{b}}\right)$. Simultaneously, the chemical exergy of the combustion gases is formed. Subsequently, $\dot{E}_{\dot{Q}_{b}}$ produces a physical exergy change between States 04 and 03 . The products of the high and low expansion turbines are the power generated to mechanically drive the $C$ and $F$. They use the differences between the physical exergies of their corresponding exiting and entering combustion gases as resources. Finally, the productive purposes of the FN and $\mathrm{N}$ are to accelerate and exhaust cold air and combustion gases, respectively. Their products are the kinetic exergies in States 7 and 8 . The resource of each nozzle is the difference between the stagnant physical exergy at the entrance and the static physical exergy at the exit of each of the productive components.

Figure 2 shows the productive structure. The set of dissipative components conforms to cold, hot, and chemical stacks: $\mathscr{D}=\{\mathrm{cS}, \mathrm{hS}, \mathrm{chS}\}$. These components do not generate any product; their purpose is to expel the residual exergy flows created during the production process to the environment $[13,28,29]$. The physical exergies of the exhausted air and combustion gases are the 
resources of $\mathrm{cS}$ and $\mathrm{hS}$, respectively. The exergy associated with the heat transferred from the air and exhaust gases to the environment $\left(\dot{E}_{\dot{Q}_{c}}\right.$ and $\dot{E}_{\dot{Q}_{h}}$ ) are the residues of these dissipative components. The chemical exergy of the exhausted combustion gases is the fuel and residue of the chemical stack. The exergy of these three residues is destroyed in the environment, which closes the open cycle, but causes harm to the environment. For aircraft engines, the exergy of residues cannot be reused; therefore, the residues can be considered as exergy losses.

The productive structure indicates the productive components participating in the formation of the turbofan product $\dot{E}_{8}^{K}$ and residual exergy flow $\dot{E}_{8}^{P H}: \mathscr{P}_{c S}=\{\mathrm{D}, \mathrm{F}\}$. The formation of the product $\dot{E}_{7}^{K}$ and residual exergy $\dot{E}_{7}^{P H}$ is given by $\mathscr{P}_{h S}=\{\mathrm{D}, \mathrm{F}, \mathrm{C}, \mathrm{CC}\}$. Finally, the chemical exergy of the exhausted combustion gases $\left(\dot{E}_{7}^{C H}\right)$ forms only in the CC: $\mathscr{P}_{c h s}=\{\mathrm{CC}\}$.

\subsection{Exergy Balance Equations}

Table 3 presents the exergy balances of the turbofan components that belong to the bypass (cold-air side) and two-shaft Brayton cycle (hot-air side) sections.

Table 3. Resources, products, residues, and irreversibilities of the turbofan components.

\begin{tabular}{|c|c|c|c|c|}
\hline Component & $\dot{\boldsymbol{F}}$ & $\dot{P}$ & $\dot{R}$ & $\dot{I}$ \\
\hline \multicolumn{5}{|c|}{ Cold-air side (Bypass section) } \\
\hline \multirow{2}{*}{$\mathrm{D}$} & $\underline{\beta \dot{E}_{a}^{K}}$ & $\beta \dot{E}_{t 1}^{P H}$ & 0 & $\underline{\beta\left(\dot{S}_{1}-\dot{S}_{a}\right)}$ \\
\hline & $\overline{1+\beta}$ & $\overline{1+\beta}$ & 0 & $1_{0} \overline{1+\beta}$ \\
\hline \multirow{2}{*}{$\mathrm{F}$} & $\underline{\beta \dot{W}_{F}}$ & $\underline{\beta\left(\dot{E}_{t 2}^{P H}-\dot{E}_{t 1}^{P H}\right)}$ & 0 & $T_{0} \underline{\beta\left(\dot{S}_{2}-\dot{S}_{1}\right)}$ \\
\hline & $\begin{array}{c}\overline{1+\beta} \\
\beta \dot{E}_{t 2}^{P H}-(1+\beta) \dot{E}_{8}^{P H}\end{array}$ & $1+\beta$ & \multirow[b]{2}{*}{0} & $\begin{array}{c}1_{0} \frac{1+\beta}{(1+\beta) \dot{S}_{8}-\beta \dot{S}_{2}}\end{array}$ \\
\hline $\mathrm{FN}$ & $\frac{\beta-t 2}{1+\beta}$ & \multirow[t]{2}{*}{$\dot{E}_{8}^{K}$} & & $T_{0} \frac{1+\beta}{1+\beta}$ \\
\hline \multirow[t]{2}{*}{ cS } & $\dot{E}_{8}^{P H}$ & & $\dot{E}_{\dot{Q}_{c}}$ & $T_{0}\left(\frac{Q_{0}^{\llcorner}}{\langle T\rangle_{c S t}}-\dot{S}_{8}\right)$ \\
\hline & \multicolumn{3}{|c|}{ Hot-gas side (Core engine) } & \multirow{3}{*}{$T_{0} \frac{\dot{S}_{1}-\dot{S}_{a}}{1+\beta}$} \\
\hline \multirow{2}{*}{$\mathrm{D}$} & $\dot{E}_{a}^{K}$ & $\dot{E}_{t 1}^{P H}$ & \multirow{2}{*}{0} & \\
\hline & $\overline{1+\beta}$ & $\begin{array}{c}\overline{1+\beta} \\
\dot{\Gamma}_{P H} \dot{\Gamma}^{P} P H\end{array}$ & & \\
\hline $\mathrm{F}$ & $\frac{W_{F}}{1+\beta}$ & $\frac{E_{t 2}^{1}-E_{t 1}^{1}}{1+\beta}$ & 0 & $T_{0} \frac{S_{2}-S_{1}}{1+R}$ \\
\hline \multirow[b]{2}{*}{$\mathrm{C}$} & $1+\beta$ & $\begin{array}{c}1+\beta \\
\dot{E}_{t 3}^{P H}-\dot{E}_{t 2}^{P H}\end{array}$ & \multirow{2}{*}{0} & $\begin{array}{c}1+\beta \\
(1+\beta) \dot{S}_{3}-\dot{S}_{2}\end{array}$ \\
\hline & $W_{C}$ & $\frac{10}{1+\beta}$ & & $T_{0}-\frac{1}{1+\beta}$ \\
\hline $\mathrm{CC}$ & $\dot{E}_{f}$ & $\dot{E}_{t 4}-\dot{E}_{t 3}$ & 0 & $T_{0}\left(\dot{S}_{4}-\dot{S}_{3}\right)$ \\
\hline HPT & $\dot{E}_{t 4}^{P H}-\dot{E}_{t 5}^{P H}$ & $\dot{W}_{H P T}$ & 0 & $T_{0}\left(\dot{S}_{5}-\dot{S}_{4}\right)$ \\
\hline LPT & $\dot{E}_{t 5}^{P H}-\dot{E}_{t 6}^{P H}$ & $\dot{W}_{L P T}$ & 0 & $T_{0}\left(\dot{S}_{6}-\dot{S}_{5}\right)$ \\
\hline $\mathrm{N}$ & $\dot{E}_{t 6}-\dot{E}_{7}$ & $\dot{E}_{7}^{K}$ & 0 & $T_{0}\left(\dot{S}_{7}-\dot{S}_{6}\right)$ \\
\hline hS & $\dot{E}_{7}^{P H}$ & & $\dot{E}_{\dot{Q}_{h}}$ & $T_{0}\left(\frac{\dot{Q}_{0}^{h}}{\langle T\rangle_{h S}}-\dot{S}_{7}\right)$ \\
\hline $\operatorname{chS}$ & $\dot{E}_{7}^{C H}$ & & $\dot{E}_{7}^{C H}$ & $T_{0}\left(\frac{\dot{Q}_{0}^{h}}{\langle T\rangle_{h S t}}-\dot{S}_{7}\right)$ \\
\hline
\end{tabular}

The exergy balances for the productive components are based on the resource-product definition: $\dot{F}_{i}=\dot{P}_{i}+\dot{I}_{i}$, where $\dot{F}_{i}$ and $\dot{P}_{i}$ are the resource and product exergy flows, respectively, and $\dot{I}_{i}$ is the irreversibility exergy flow. The exergy efficiency of the $i$ th productive component quantifies its useful exergy and is defined as $\eta_{e x, i}=\dot{P}_{i} / \dot{F}_{i}$. The reciprocal of the exergy efficiency is the unit exergy consumption $\kappa_{i}=1 / \eta_{e x, i}$ and is the resource required to generate one unit exergy of the product.

\subsection{Fuel-Product-Residue Table}

Table 4 corresponds to the FPR table of the turbofan, which is a mathematical representation of the thermoeconomic model and represents the distribution of resources and products throughout the 
engine according to its productive structure. It gives the values of flows in the productive structure shown in Figure 2 as a combination of the flows of the physical structure depicted in Figure 1 [30].

Table 4. FPR table and recirculation coefficients for the turbofan.

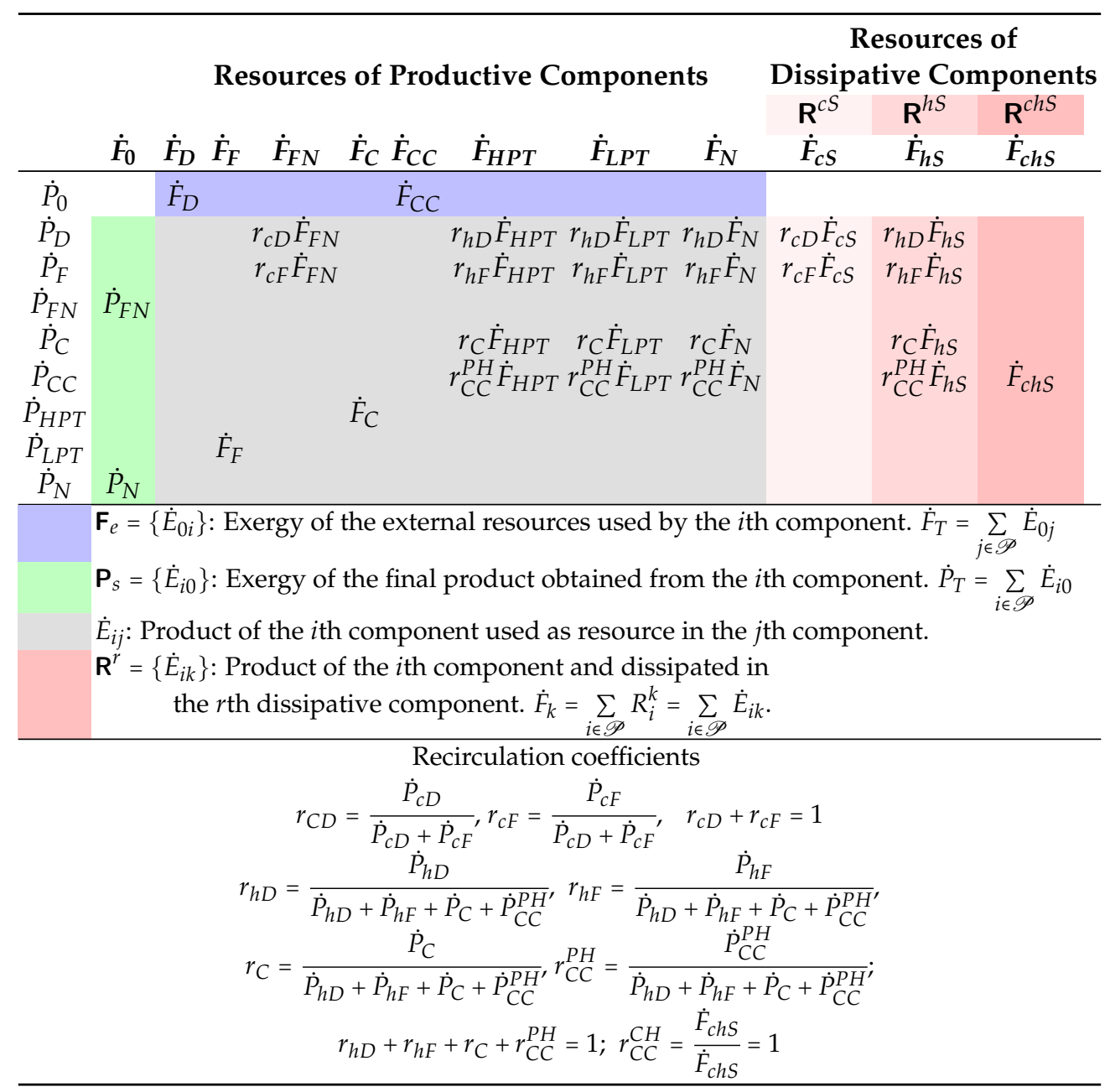

The first column of Table 4 represents the product exergy flow obtained from each productive component, and the first row represents the external resources entering the system [27]. Each column associated with the productive components represents how the resource of a given component comes from other components or from the environment [30]. The $i$ th element of each column of dissipative components corresponds to the portion of the resource (i.e., residue) responsible for treating and eliminating it, which originates from and is allocated to the $i$ th component. The rows represent the destinations of the products of each component as resources of other components, the primary product of the system, or residual exergy flows of the system corresponding to the resources of dissipative components [27]. Each row illustrates two chains in the production process: the formation of the final product and, in the opposite direction, the formation and allocation of residues generated during the production process.

\section{Exergoeconomic Cost Analysis}

\subsection{Residue Formation Cost}

The formation costs of residues must be rationally allocated to the functional system products. This analysis is based on the premise that residues are formed within the productive components and released to the environment from the dissipative components, where they are treated with additional 
resources, and whose abatement costs are charged to the productive components. The exergoeconomic cost of a residue $\left(\dot{\Pi}_{\dot{R}_{r}}\right)$ has three contributions: the residue formation cost that corresponds to the exergy in a residual exergy flow, which is the resource of a dissipative component $\left(\dot{\Pi}_{\dot{F}_{r}}\right)$; the cost of additional exergetic resources employed for its elimination $\left(\dot{\Pi}_{\dot{F}_{o r}}\right)$; the non-exergetic abatement costs required for its elimination $\left(\dot{Z}_{r}\right)$. The cost balance for the $r$ th dissipative component takes the form [13]:

$$
\dot{\Pi}_{\dot{R}_{r}}=\dot{\Pi}_{\dot{F}_{r}}+\dot{\Pi}_{\dot{F}_{a r}}+\dot{Z}_{r}, r \in \mathscr{D}
$$

The residues of the turbofan engine are exergy losses because they leave the stacks without any further use, so their exergy and exergoeconomic costs are zero. For all the flight phases, $\dot{\Pi}_{\dot{R}_{r}}=0=\dot{R}_{r}^{*}$ for all $r \in \mathscr{D}$. Because the stacks are imaginary dissipative components, there are no abatement costs for these losses (i.e., $\dot{Z}_{r}=0$ for all $r \in \mathscr{D}$ ). The aircraft losses come from the residual physical exergies of the air and exhaust gases $\left(\dot{F}_{c S}=\dot{E}_{8}^{P H}\right.$ and $\left.\dot{F}_{h S}=\dot{E}_{7}^{P H}\right)$ formed in the productive components of $\mathscr{P}_{c S}$ and $\mathscr{P}_{h S}$, whereas the chemical exergy of the exhaust gases forms only in the CC $\left(\dot{F}_{c h S}=\dot{E}_{7}^{C H}=\dot{E}_{4}^{C H}\right)$. According to Equation (15), the cost balance for the cold, hot, and chemical stacks is:

$$
\dot{\Pi}_{\dot{F}_{r}}=-\dot{\Pi}_{\dot{F}_{a r}}>0, r \in \mathscr{D}=\{\mathrm{cS}, \mathrm{hS}, \mathrm{chS}\}
$$

In this case study, the dissipative components were not part of the energy system. If it is desired that these components are charged with the elimination costs, Equation (16) indicates that a negative value must be allocated to the cost of $\dot{F}_{r}$ as an output stream of the system [31]. This is only a case of internalizing the costs taking place downstream of the main process. These costs must be allocated to the productive components involved in the formation cost of each residue. In this manner, the formation cost of a residue $\left(\dot{\Pi}_{\dot{F}_{r}}\right)$ is decomposed into several costs corresponding to the originating components.

$$
\dot{\Pi}_{\dot{F}_{r}}=\sum_{i \in \mathscr{P}_{r}} \dot{\Pi}_{\dot{F}_{r i}}, r \in \mathscr{D}
$$

where $\mathscr{P}_{r}$ is the set of productive components that generate the residue dissipated in the $r$ th dissipative component $\left(\mathscr{P}_{c S}, \mathscr{P}_{h S}\right.$, and $\left.\mathscr{P}_{c h S}\right)$ and $\dot{\Pi}_{\dot{F}_{r i}}$ is the formation cost of the residue dissipated in the $r$ th component that has been generated by the $i$ th productive component. The formation cost of the residues charged to the $i$ th productive component is given by:

$$
\dot{\Pi}_{\dot{F}_{R i}}=\dot{\Pi}_{\dot{F}_{c S, i}}+\dot{\Pi}_{\dot{F}_{h S, i}}+\dot{\Pi}_{\dot{F}_{c h S, i}}
$$

To determine the values of $\dot{\Pi}_{\dot{F}_{r i}}$ thermoeconomics defines the residue cost allocation ratios. For a given residue dissipated in the $r$ th dissipative component, the residue cost allocation ratio associated with the $i$ th productive component $\left(\mu_{i}^{r}\right)$ is the fraction of the residue cost allocated to this component.

$$
\dot{\Pi}_{\dot{F}_{r i}}=\mu_{i}^{r} \dot{\Pi}_{\dot{F}_{r}}, \text { with } \sum_{i \in \mathscr{P}_{r}} \mu_{i}^{r}=1, r \in \mathscr{D}
$$

These ratios determine how the cost of a residue should be decomposed into several costs. However, there is no definitive method to determine them. A frequently used criterion is to allocate the cost of residues proportionally to entropy changes during the process [32,33]. The criterion used in this work was proposed by Valero et al. [13] to make the residue cost allocation ratios proportional to the exergy flow produced in the $i$ th component that is processed and dissipated in the $r$ th component according to the productive structure of the plant. According to the thermoeconomic theory, these ratios are known as recirculation coefficients. They can be obtained directly from the information provided by the productive structure and FPR table [34,35]. For the turbofan engine, they are defined in Table 4 . 


\subsection{Production Costs}

In this study, the symbolic thermoeconomic methodology [17] was used to calculate the production costs. The FPR table (Table 4) was used as the starting point to numerically calculate the costs of the system flows. This methodology is derived from the application of the extended cost propositions of the ECT, one of which is that the cost of residues is generated by the productive components from which they originate $[10,13]$.

- The costs of the external resources are known: $\dot{\Pi}_{\dot{E}_{f}}=c_{f} \dot{E}_{f}$ and $\dot{\Pi}_{\dot{E}_{a}}=c_{a} \dot{E}_{a}$.

- The production cost of the $i$ th productive component $\left(\dot{\Pi}_{\dot{P}_{i}}\right)$ is the sum of the cost of resources required to obtain it $\left(\dot{\Pi}_{\dot{F}_{i}}\right)$, the formation cost of residues allocated to this component $\left(\dot{\Pi}_{\dot{F} R_{i}}\right)$ (Equation (18)), and the purchase cost of the component $\left(\dot{Z}_{i}\right) . \dot{\Pi}_{\dot{P}_{i}}=\dot{\Pi}_{\dot{F}_{i}}+\dot{\Pi}_{\dot{F}_{R i}}+\dot{Z}_{i}, i \in \mathscr{P}$.

- If a component has a product comprising several flows, the same unit exergoeconomic cost is assigned to them. In fact, even if two or more products can be identified in the same component, their formation processes are inseparable at the considered level of aggregation.

Symbolic thermoeconomics has two ways to determine the production costs of a system, including the effects of residues: the PFR and FPR models (see Table A4). In the PFR model, the thermoeconomic variables are functions of the recirculation coefficients, system products, and unit consumption of the components. This is commonly applied when the total production is fixed and the resource consumption varies. The FPR model is the most suitable for numerically calculating the production costs because it relates any exergoeconomic production cost with the external resources through a linear function of the distribution coefficients:

$$
\begin{aligned}
\boldsymbol{\Pi}_{P}=\left\langle\mathbf{P}^{*}\right|\left(\boldsymbol{\Pi}_{e}+\mathbf{Z}\right), & \text { where }\left\langle\mathbf{P}^{*}\right|=\left(\mathbf{U}_{D}-\langle\mathbf{F P}\rangle-\langle\mathbf{R P}\rangle\right)^{-1} \\
& \boldsymbol{\Pi}_{F}=\boldsymbol{\Pi}_{e}+\langle\mathbf{F P}\rangle \boldsymbol{\Pi}_{P} \\
& \boldsymbol{\Pi}_{F_{R}}=\langle\mathbf{R P}\rangle \boldsymbol{\Pi}_{P}
\end{aligned}
$$

where $\langle\mathbf{F P}\rangle$ and $\langle\mathbf{R P}\rangle$ are square matrices of $n \times n$. Their elements are distribution coefficients defined respectively by $y_{i j}=\dot{E}_{j i} / \dot{P}_{j}$ and $\psi_{r j}=\dot{R}_{j r} / \dot{P}_{j}$ and satisfy $\sum_{i \in \mathscr{P}}\left(y_{i j}+\psi_{i j}\right)=1$. This model can decompose the exergoeconomic cost of products into three contributions: energy resources $\left(\Pi_{P}^{e}\right)$, component costs $\left(\Pi_{P}^{Z}\right)$, and residue costs $\left(\Pi_{P}^{r}\right)$ (Equation (21)).

$$
\boldsymbol{\Pi}_{P}=\left\langle\mathbf{P}^{* *}\right|\left(\boldsymbol{\Pi}_{e}+\mathbf{Z}+\boldsymbol{\Pi}_{R}\right)=\boldsymbol{\Pi}_{P}^{e}+\boldsymbol{\Pi}_{P}^{Z}+\boldsymbol{\Pi}_{P}^{r}
$$

Here, $\left\langle\mathbf{P}^{* *}\right|=\left(\mathbf{U}_{D}-\langle\mathbf{F P}\rangle\right)^{-1}$ indicates the proportion at which the cost increases owing to the internal and external irreversibilities of each component. The most important application of calculating the costs of internal streams is to assess the impact of the additional fuel to compensate component malfunctions (inefficiences).

\section{Operational Diagnosis of the Fuel Impact}

\subsection{Fuel Impact in Terms of Malfunctions and Dysfunctions}

A thermoeconomic diagnosis is based on a comparison of two operating conditions of a process: the actual and reference conditions denoted by the states $\mathbf{x}$ and $\mathbf{x}_{0}$, respectively. The reference condition is commonly the design condition, the state of the plant after an overhaul, or the state after an acceptance test [36]. However, the reference condition can also be associated with a change in the environmental conditions, a change in fuel quality, operation at partial load, or intervention from the control system. The objective of the diagnosis is to identify and quantify the additional resource consumption $\left(\Delta \dot{F}_{T}=\dot{F}(\mathbf{x})-\dot{F}\left(\mathbf{x}_{0}\right)\right)$ caused by the increases in component irreversibilities $\left(\Delta \dot{I}_{T}\right)[19,37]$. The fuel impact is the sum of the variations in the exergy destroyed by each component 
(internal irreversibility $\Delta \mathbf{I}$ ), exergy delivered to the environment (external irreversibility $\Delta \mathbf{R}$ ), and total production $\left(\Delta \mathbf{P}_{s}\right)$.

$$
\Delta F_{T}=\mathbf{u}^{t}\left(\Delta \mathbf{l}+\Delta \mathbf{R}+\Delta \mathbf{P}_{S}\right)
$$

The variation in internal and external irreversibilities $(\Delta \mathbf{I}+\Delta \mathbf{R})$ on the right side of Equation (22) is known as the exergy technical savings and represents the irreversibility attributed to improper operation of the components that can be avoided.

The fuel impact defined by Equation (22) can be expressed in terms of malfunctions and dysfunctions.

$$
\Delta \dot{F}_{T}=\mathbf{u}^{t}\left(\mathbf{M F}_{e}^{t}+\mathbf{M} \mathbf{F}^{t}+\mathbf{M} \mathbf{R}^{t}+\mathbf{D} \mathbf{F}_{K}+\mathbf{D} \mathbf{F}_{\Delta \mathbf{P}_{s}}\right)
$$

Malfunctions are the endogenous irreversibility variations and can be divided into internal and external malfunctions. The internal malfunction of a component is an irreversibility variation in such a component due to the variation of the exergy unit consumption of resources coming from the environment $\left(\mathbf{M F}_{e}^{t}=\left(\Delta \mathbf{K}_{D}-\Delta\langle\mathbf{K} \mathbf{P}\rangle\right) \mathbf{P}\left(x_{0}\right)\right)$ or from other productive components of the energy system $\left(\mathbf{M F}^{t}=\Delta\langle\mathbf{K} \mathbf{P}\rangle \mathbf{P}\left(x_{0}\right)\right)$ [38]. External malfunction is due to the yielding variations of residues in each component $\left(\mathbf{M} \mathbf{R}^{t}=\Delta\langle\mathbf{K R}\rangle \mathbf{P}\left(x_{0}\right)\right)$.

Dysfunctions are exogenous irreversibility variations in a component. They are induced by the malfunctions of other components, which force the component to consume more or less resources in order to satisfy its local production $\left(\mathbf{D F}_{K}=[|\mathbf{I}\rangle(x)+|\mathbf{R}\rangle(x)]\left(\mathbf{M} \mathbf{F}^{t}+\mathbf{M R}^{t}\right)\right)$ and the total production of the energy system $\left(\mathbf{D F}_{\Delta \mathbf{P}_{s}}=\left[\mathbf{U}_{D}+|\mathbf{I}\rangle(x)+|\mathbf{R}\rangle(x)\right] \Delta \mathbf{P}_{s}\right)$. The dysfunction of a component depends on its position in the system and can be reduced only if the malfunction is reduced.

The fuel impact can also be conceived of as the sum of the cost of the total malfunctions; see Equation (24). The malfunction cost of a component is the sum of the malfunction and the dysfunctions that it induces: $\mathbf{M F}_{e}^{* t}=\mathbf{M F}_{e}^{t}, \mathbf{M F}^{* t}=\mathbf{M} \mathbf{F}^{t}+|\mathbf{I}\rangle(x)\left(\mathbf{M} \mathbf{F}^{t}+\mathbf{M} \mathbf{R}^{t}\right), \mathbf{M R}^{* t}=\mathbf{M R}^{t}+$ $|\mathbf{R}\rangle(x)\left(\mathbf{M F}^{t}+\mathbf{M R}^{t}\right)$.

$$
\Delta \dot{F}_{T}=\mathbf{u}^{t}\left(\mathbf{M F}_{e}^{\star t}+\mathbf{M F}^{\star t}+\mathbf{M R}^{\star t}+\mathbf{D F}_{\Delta \mathbf{P}_{s}}\right)
$$

The fuel impact can also be conceived of as the sum of the cost of the total malfunctions. The cost of each malfunction represents the additional fuel plant consumption due to the existence of an intrinsic malfunction, such as the inefficiency of the corresponding component that forces the rest of the plant components to adapt their operating conditions and provoking induced malfunctions [39].

For a turbofan engine, the combination of the vehicle model and mission profile provides a thrust requirement that depends on the total exergy production given in Equation (4). Because all the equations presented in this section include the variation in the total production, they indicate that, in the presence of a malfunction, the production of an aircraft engine should also be adjusted to satisfy the thrust requirement.

\subsection{Fuel Impact Expressed as an Exergoeconomic Cost}

The fuel impact can be expressed as an economic cost related to a change in operating conditions and corresponds to a variation in the exergoeconomic cost of external resources $\left(\Delta \boldsymbol{\Pi}_{e}=\Pi_{e}(\mathbf{x})-\Pi_{e}\left(\mathbf{x}_{0}\right)\right)$ [18]. Table A4 indicates that $\boldsymbol{\Pi}_{e}=\mathbf{P}_{D} \mathbf{c}_{e P}$, and therefore, the economic cost of the fuel impact can be divided into exergoeconomic costs due to variations between the actual and reference conditions in the cost of external resources, malfunctions, and final product: 


$$
\Delta \boldsymbol{\Pi}_{e}^{t} \mathbf{u}=\underbrace{\Delta \mathbf{c}_{P e}^{t} \mathbf{P}\left(\mathbf{x}_{0}\right)}_{\begin{array}{c}
\text { Exergoeconomic cost due to } \\
\text { variations in the products and /or } \\
\begin{array}{c}
\text { exergoeconomic cost } \\
\text { of external resources }
\end{array}
\end{array}}+\underbrace{\mathbf{c}_{P e}^{t}(\mathbf{x})|\mathbf{P}\rangle(\mathbf{x})\left(\mathbf{M} \mathbf{F}^{t}+\mathbf{M R}^{t}\right)}_{\begin{array}{c}
\text { Exergoeconomic cost } \\
\text { due to malfunctions }
\end{array}}+\underbrace{\mathbf{c}_{P e}^{t}(\mathbf{x})|\mathbf{P}\rangle(\mathbf{x}) \Delta \mathbf{P}_{s}}_{\begin{array}{c}
\text { Exergoeconomic cost } \\
\text { produced by variations } \\
\text { in the final product }
\end{array}}
$$

The difference in economic costs between the actual and reference operating conditions associated with the changes in exergy consumption by the engine $\left(\Delta \dot{F}_{T}\right)$ and capital and maintenance costs is given by:

$$
\begin{aligned}
\left(\Delta \boldsymbol{\Pi}_{e}+\Delta \mathbf{Z}\right)^{t} \mathbf{u}=\left(\Delta \mathbf{c}_{P e}^{t}+\Delta \mathbf{c}_{P z}^{t}\right) \mathbf{P}\left(\mathbf{x}_{0}\right)+\left[\mathbf{c}_{P e}^{t}(\mathbf{x})\right. & \left.+\mathbf{c}_{P z}^{t}(\mathbf{x})\right]|\mathbf{P}\rangle(\mathbf{x})\left(\mathbf{M} \mathbf{F}^{t}+\mathbf{M R}^{t}\right) \\
& +\left[\mathbf{c}_{P e}^{t}(\mathbf{x})+\mathbf{c}_{P z}^{t}(\mathbf{x})\right]|\mathbf{P}\rangle(\mathbf{x}) \Delta \mathbf{P}_{s}
\end{aligned}
$$

where $\mathbf{c}_{P z}$ is the vector of the capital and maintenance costs per unit product.

\section{Results and Discussion}

In this work, the residue formation cost was determined for a GE90-115B high bypass turbofan engine with a thrust requirement of $510 \mathrm{kN}$ in the takeoff condition, and a malfunction analysis was also performed. The technical design data of the engine are presented in Table 5.

Table 5. Technical design data of the GE90-115B [40]: component efficiencies, pressure ratios, ambient conditions, and fuel properties [21].

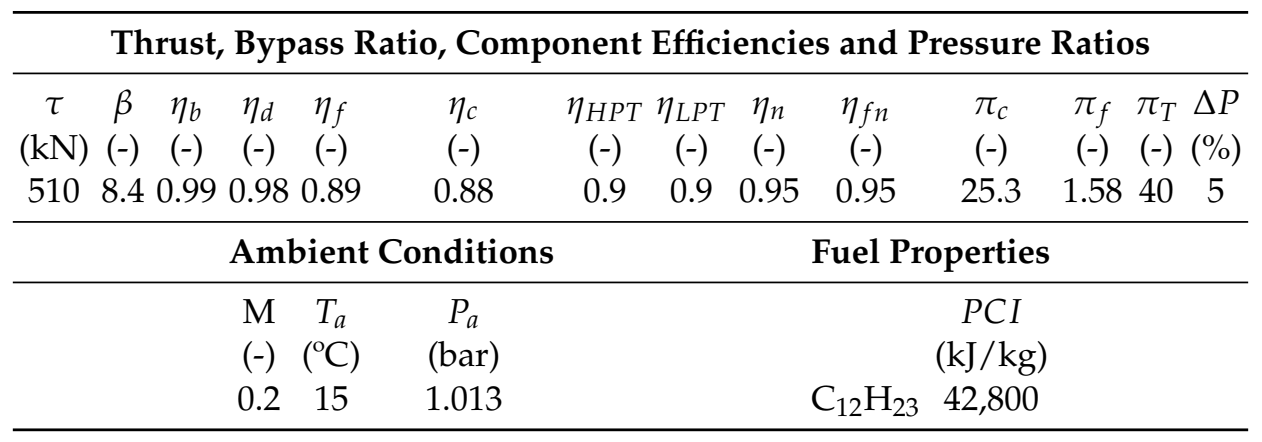

In the sea level static condition and maximum power setting (takeoff condition), the thermodynamic states of the engine are presented in Table A1. From this thermodynamic data, it was found that the GE90-115B high bypass turbofan engine produced a kinetic exergy rate of 89.29 MW while consuming $5.86 \mathrm{~kg} / \mathrm{s}$ of Jet-A fuel. The thermal and propulsive efficiencies of the engine were estimated to be $37.48 \%$ and $37.25 \%$, respectively.

\subsection{Exergy Analysis}

Table 6 presents the FPR table for the analyzed aircraft engine as defined in Table 4. Each row indicates how the product of each component was distributed among the other components and the environment, either as a useful product or residue. Each column represents how the resource of a given component came from another component or from the environment [30]. In Table 6, the CC column shows how the resource of the CC was equal to $266.34 \mathrm{MW}$ coming from the environment. The CC row shows that the CC product was equal to 186.59 MW, which went to the HPT (78.97 MW), LPT (59.07 MW), N (8.79 MW), and hot and chemical stacks (31.93 and 7.84 MW, respectively). A similar analysis can be made for the other components. 
Table 6. FPR table for the turbofan engine in MW.

\begin{tabular}{|c|c|c|c|c|c|c|c|c|c|c|c|c|}
\hline & \multirow[b]{2}{*}{$\dot{F}_{0}$} & \multirow[b]{2}{*}{$\dot{F}_{D}$} & \multicolumn{6}{|c|}{ Productive Components } & \multicolumn{3}{|c|}{$\begin{array}{l}\text { Dissipative } \\
\text { Components }\end{array}$} & \multirow{2}{*}{ Total } \\
\hline & & & $\dot{F}_{F}$ & $\dot{\boldsymbol{F}}_{F N}$ & $\dot{F}_{C}$ & $\dot{F}_{C C}$ & $\dot{F}_{H P T}$ & $\dot{F}_{L P T}$ & $\dot{\boldsymbol{F}}_{N}$ & $\begin{array}{l}\mathrm{R}^{c S} \\
\dot{F}_{c S}\end{array}$ & $\begin{array}{ll}\mathbf{R}^{h S} & \mathbf{R}^{c h S} \\
\dot{F}_{h S} & \dot{F}_{c h S}\end{array}$ & \\
\hline$\dot{P}_{0}$ & & 5.17 & & & & 266.34 & & & & & & 271.51 \\
\hline$\dot{P}_{D}$ & & & & 4.52 & & & 0.24 & 0.18 & 0.03 & 0.01 & 0.10 & 5.07 \\
\hline$\dot{P}_{F}$ & & & & 82.53 & & & 4.35 & 3.25 & 0.48 & 0.14 & 1.76 & 92.51 \\
\hline$\dot{P}_{F N}$ & 82.78 & & & & & & & & & & & 82.78 \\
\hline$\dot{P}_{C}$ & & & & & & & 58.68 & 43.89 & 6.53 & & 23.72 & 132.82 \\
\hline$\dot{P}_{C C}$ & & & & & & & 78.97 & 59.07 & 8.79 & & 31.937 .84 & 186.59 \\
\hline$\dot{P}_{H P T}$ & & & & & 138.26 & & & & & & & 138.26 \\
\hline$\dot{P}_{L P T}$ & & & 102.23 & & & & & & & & & 102.23 \\
\hline$\dot{P}_{N}$ & 15.51 & & & & & & & & & & & 15.51 \\
\hline Total & 98.29 & 5.17 & 102.23 & 87.05 & 138.26 & 266.34 & 142.23 & 106.39 & 15.82 & 0.15 & 57.517 .84 & \\
\hline
\end{tabular}

A Grassmann diagram is a graphic representation of the exergy accounting in energy systems and highlights the exergy flows and where the potential improvements exist. The Grassmann diagram of the GE90-115B high bypass turbofan engine, which is fueled with an exergy flow of $271.51 \mathrm{MW}$ in takeoff conditions, is shown in Figure 3 and is plotted in agreement with Table A2. This diagram indicates that only $36.20 \%$ of the resources were used to produce the useful kinetic exergy in the bypass $(30.49 \%$, $\left.\dot{E}_{8}\right)$ and the core engine $\left(5.71 \%, \dot{E}_{7}\right)$; the exergy destroyed in the productive components (internal irreversibilities) was $39.68 \%$; and the remaining $24.12 \%$ was waste exergy (external irreversibilities) corresponding to the chemical exergy of the combustion gases $\left(2.88 \%, \dot{R}^{c h S}\right)$ and the physical exergy of the exhaust combustion gases and air $\left(21.18 \%\right.$ and $0.06 \%$, respectively, $\left.\dot{R}^{h S}, \dot{R}^{c S}\right)$. Approximately $30 \%$ of the fuel exergy was destroyed during the combustion process and represents the biggest irreversibility.

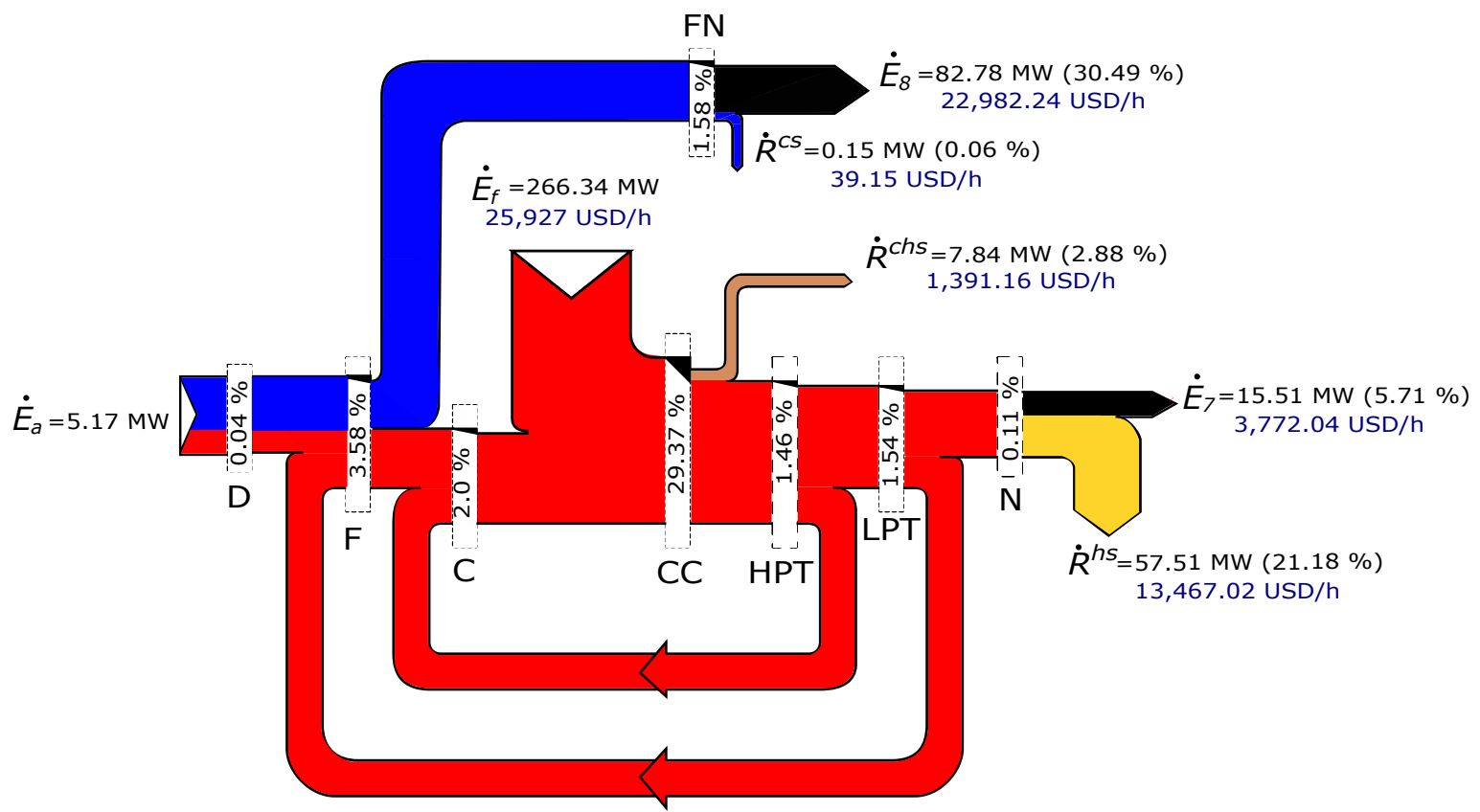

Figure 3. Grassmann diagram of the GE90-11B turbofan engine in the takeoff condition.

\subsection{Exergoeconomic Analysis}

The total cost of the kinetic exergy produced by the GE90-115B turbofan engine in the takeoff condition was $26,745.28 \mathrm{USD} / \mathrm{h}, 86.0 \%$ attributable to the exergy produced in the bypass section $\left(\dot{\Pi}_{P}^{F N}=\right.$ $22,982.24 \mathrm{USD} / \mathrm{h})$ and the remaining part to that generated in the core engine $\left(\dot{\Pi}_{P}^{N}=3772.04 \mathrm{USD} / \mathrm{h}\right)$; 
see the first column of Table A3. Figure 4 presents the production costs of each productive component as the sum of the external resources cost, residues cost, and components cost. This figure indicates that the cost of jet fuel, residues, and components contributed to the production cost of the turbofan engine as $61.06 \%, 36.50 \%$, and $2.47 \%$, respectively (see FN and N bars of Figure 4 and FN and F rows of Table A3).

Despite the difficulty in accurately estimating component costs, Figure 4 shows that the fuel cost had the largest contribution to the production cost of the different components $(51.22-78.34 \%$ for all the productive components except for the diffuser). This figure also illustrates that the residue cost was greater than the component cost except for the D. Among the residues, the waste heat dissipated from the core engine had the largest impact (1.9\% for the D, $17.11 \%$ for the CC $44.24 \%$ for the $\mathrm{C}$, and $31.87-33.36 \%$ for the other productive components), followed by the chemical exergy of the exhaust gases $(0.00 \%$ for the D, $4.20 \%$ for the CC, $2.75 \%$ for the $C$, and $3.27-3.37 \%$ for the other productive components) and the waste heat dissipated from the FN $(0.00 \%$ for the CC, $0.16 \%$ for the F and $\mathrm{FN}$, and $0.008-0.01 \%$ for the other productive components).

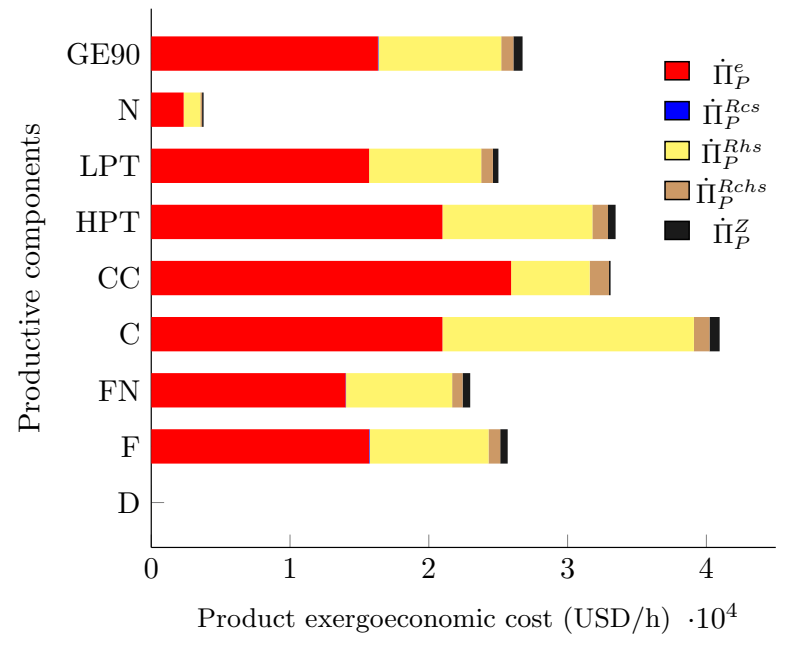

Figure 4. Production exergoeconomic cost decomposition, $\boldsymbol{\Pi}_{P}=\boldsymbol{\Pi}_{P}^{e}+\boldsymbol{\Pi}_{P}^{r}+\boldsymbol{\Pi}_{P}^{Z}$.

\subsection{Malfunction Analysis}

A malfunction analysis was performed on the turbofan engine by decreasing the compressor isentropic efficiency by $1 \%$ at a constant thrust requirement of $\tau=501 \mathrm{kN}$. The decrease in compressor efficiency had a fuel impact of $\Delta \dot{F}_{T}=0.49 \mathrm{MW}$, a kinetic exergy production impact of $\Delta \dot{P}_{T}=-0.77 \mathrm{MW}$, an irreversibility impact of $\Delta \dot{I}_{T}=0.80 \mathrm{MW}$, and a residue formation impact of $\Delta \dot{R}=0.45 \mathrm{MW}$.

Table 7 presents the contributions to the fuel impact caused by the compressor degradation according to the decompositions given by Equations (22)-(24). The last column of this table shows the contribution of each component to the fuel impact and reveals that the highest additional fuel engine consumption was assessed for compressor $(0.87 \mathrm{MW})$, which was the component where the inefficiency occurred. The first three columns of Table 7 correspond to the decomposition of the fuel impact in terms of the component variations of irreversibility, residues, and products. This part of the mentioned table shows that the anomaly in the compressor made it the component that contributed the most to the fuel impact of irreversibility and residues (0.50 MW and 0.38 MW, respectively). This means that the compressor malfunction increased its irreversibility by $62.1 \%$ and the residues allocated to this component by $83.1 \%$. The compressor inefficiency modified the engine operation such that the FN produced more kinetic exergy $\left(\Delta \dot{P}_{F N}=0.81 \mathrm{MW}\right)$ and $\mathrm{N}$ reduced its kinetic energy production $\left(\Delta \dot{P}_{F N}=-1.58 \mathrm{MW}\right)$. The compressor degradation propagated the anomalies by increasing the irreversibility in all components except for the $\mathrm{D}$ and $\mathrm{N}$ of the core engine and by increasing the 
exergy of the residues allocated to the $C C\left(\Delta \dot{R}_{C C}=0.06 \mathrm{MW}\right)$. The compressor anomaly not only caused an increase of the resource consumption, but it also caused an increase of the residue generation.

Table 7. Fuel impact decomposition.

\begin{tabular}{|c|c|c|c|c|c|c|c|c|c|c|c|}
\hline & \multicolumn{3}{|c|}{ Equation (22) } & \multicolumn{5}{|c|}{ Equation (23) } & \multicolumn{2}{|c|}{ Equation (24) } & \multirow[b]{2}{*}{$\begin{array}{l}\text { Sum } \\
\text { (MW) }\end{array}$} \\
\hline & $\Delta \mathbf{I}$ & $\begin{array}{c}\Delta \mathrm{R} \\
(\mathrm{MW})\end{array}$ & $\Delta \mathbf{P}_{S}$ & $\mathrm{MF}_{e}^{t}$ & $\mathbf{M F}^{t}$ & $\begin{array}{l}\mathrm{MR}^{t} \\
(\mathrm{MW})\end{array}$ & $\mathbf{D F}_{k}$ & $\mathbf{D F}_{\Delta \mathbf{P}_{s}}$ & $\begin{array}{r}\mathrm{MF}_{e}^{* t} \\
+\mathrm{MFR}^{\star} \\
\text { (N }\end{array}$ & $\mathrm{DF}_{\Delta \mathbf{P}_{s}}$ & \\
\hline D & 0.00 & 0.00 & 0.00 & 0.00 & 0.00 & 0.00 & 0.00 & 0.00 & 0.00 & 0.00 & 0.00 \\
\hline $\mathrm{F}$ & 0.10 & 0.02 & 0.00 & -0.01 & 0.01 & 0.00 & $0 .($ & & & & \\
\hline FN & 0.04 & 0.00 & 0.81 & 0.00 & 0.00 & 0.00 & $0 .($ & & & & 0.85 \\
\hline $\mathrm{C}$ & 0.50 & 0.38 & 0.00 & -0.55 & 0.94 & -0.03 & 0.68 & -0.1 & 1.05 & -0.1 & 0.87 \\
\hline $\mathrm{CC}$ & 0.02 & 0.06 & 0.00 & 0.75 & -0.90 & -0.03 & 0.97 & -0.70 & 0.79 & -0.70 & 0.08 \\
\hline HPT & 0.10 & 0.00 & 0.00 & -0.38 & 0.40 & 0.00 & 0.10 & -0.02 & 0.12 & -0.02 & 0.10 \\
\hline LPT & 0.07 & 0.00 & 0.00 & 0.03 & 0.00 & 0.00 & 0.01 & 0.04 & 0.04 & 0.04 & 0.07 \\
\hline $\mathrm{N}$ & -0.03 & 0.00 & -1.58 & 0.00 & 0.00 & 0.00 & 0.00 & -1.61 & 0.00 & -1.61 & -1.61 \\
\hline Sum & 0.80 & 0.45 & -0.77 & -0.15 & 0.45 & -0.06 & 1.77 & -1.52 & 2.01 & -1.52 & $\Delta \dot{F}_{T}=0.49$ \\
\hline
\end{tabular}

According to Equation (23), Table 7 exhibits the diagnosis based on the fuel impact decomposition in terms of malfunctions and dysfunctions. Columns 5 to 7 present the malfunctions due to external resource consumption variation $\left(\mathbf{M F}_{e}^{t}\right)$, component exergy consumption variation $\left(\mathbf{M F}^{t}\right)$, and the variation of component residue generation $\left(\mathbf{M R}^{t}\right)$. Since the compressor is only fueled by the power provided by the HPT and its internal malfunction was $M F_{C}=0.94 \mathrm{MW}$, the compressor required then more power to compensate its degradation and satisfy the thrust requirement. Furthermore, the combustion chamber presented a negative malfunction, $M F_{e, C C}+M F_{C C}+M R_{C C}=0.75-0.9-0.03=$ $-0.18 \mathrm{MW}$, indicating that this component did not contribute globally to increase the irreversibility of the component itself. However, it presented a dysfunction of $D F_{k, C C}+D F_{\Delta \mathbf{P}_{s}, C C}=0.97-0.07=$ $0.9 \mathrm{MW}$. In the context of the loss of compressor performance, the combustion chamber increases the propagation of the irreversibility.

All the dysfunctions related to the variation in the local production of components $\left(\mathbf{D F}_{k}\right.$; see Column 9 of Table 7) were positive or null. A positive dysfunction indicates an increment in the component irreversibility of each component due to the variation of its local production caused by the malfunction of other components. All the components, except those of the bypass section, had negative dysfunctions related to final production variation dysfunctions (see Column 10 of Table 7). These kind of irreversibilities variations do not have a negative impact by themselves, as they are associated with a variation of the overall production.

Columns 10 and 11 of Table 7 correspond to the terms of the fuel impact formula given by Equation (24). Column 10 is the malfunction cost $\left(\mathbf{M F}_{e}^{* t}+\mathbf{M F R}^{* t}\right)$, which has two distinct components: the malfunction $\left(\mathbf{M F}_{e}^{t}+\mathbf{M F} \mathbf{R}^{t}\right)$ and a structural malfunction or dysfunction $\left(\mathbf{D F}_{K}\right)$. The dysfunction of a component depends on its position in the system and can be reduced only if the malfunction is reduced. The compressor inefficiency produced the most significant malfunction cost in the component itself (1.05 MW), since it covered the malfunctions and dysfunctions associated with its degradation. All the components had positive malfunction costs because the dysfunctions $\mathbf{D F}_{k}$ induced by those components to the other components were positive.

The exergoeconomic cost of the fuel impact related to the compressor deterioration is $\Delta \boldsymbol{\Pi}_{e}^{t} \mathbf{u}=42.51 \mathrm{USD} / \mathrm{h}$, see Equation (25). This value captures the exergoeconomic cost of external resources $\left(\Delta \mathbf{c}_{P e}^{t} \mathbf{P}\left(\mathbf{x}_{0}\right)\right)$, the exergoeconomic cost regarding malfunction $\left(\mathbf{c}_{P e}^{t}(\mathbf{x})|\mathbf{P}\rangle(\mathbf{x}) \mathbf{M F R}^{t}\right)$, and the exergoeconomic cost owing to final product variation between actual and reference conditions 
$\left(\mathbf{c}_{P e}^{t}(\mathbf{x})|\mathbf{P}\rangle(\mathbf{x}) \Delta \mathbf{P}_{s}\right)$, which are presented in Table 8. The compressor was the component containing the anomaly, and it was also the one with the largest exergoeconomic malfunction cost (86.33 USD $/ \mathrm{h}$ ).

Table 8. Exergoeconomic cost decomposition of fuel impact.

\begin{tabular}{cccc}
\hline & $\Delta \mathrm{c}_{P \boldsymbol{P}}^{t} \mathrm{P}\left(\mathrm{x}_{0}\right)$ & $\mathrm{c}_{P \boldsymbol{P}}^{t}(\mathrm{x})|\mathrm{P}\rangle(\mathrm{x}) \mathrm{MFR}^{t}$ & $\mathrm{c}_{\boldsymbol{P e}}^{t}(\mathrm{x})|\mathrm{P}\rangle(\mathrm{x}) \Delta \mathrm{P}_{s}$ \\
\hline $\mathrm{D}$ & 0 & 0 & 0 \\
$\mathrm{~F}$ & 0 & -0.54 & 0 \\
$\mathrm{FN}$ & 0 & 0 & 219.80 \\
$\mathrm{C}$ & 0 & 86.33 & 0 \\
$\mathrm{CC}$ & -14.72 & -5.04 & 0 \\
$\mathrm{HPT}$ & 0 & 67.72 & 0 \\
LPT & 0 & 54.39 & 0 \\
$\mathrm{~N}$ & 0 & 7.03 & -372.45 \\
\hline GE90 & -14.72 & 209.89 & -152.65 \\
\hline
\end{tabular}

\section{Conclusions}

This paper presents a general application of thermoeconomic cost accounting to a turbofan aircraft engine, in which the formation and abatement costs of residues are included. The production structure of the turbofan helped to identify where the waste would have been formed and to allocate its costs. For a turbofan engine, the waste heat dissipated in the bypass section was formed by the diffuser and fan; while the waste heat dissipated from the core engine nozzle was formed by the diffuser, fan, compressor, and combustion chamber. Finally, the chemical exergy of exhaust gases was produced only by the combustion chamber. This work intended to show that residue allocation has a considerable effect on the computation of the production cost, and it becomes important when these costs are used in the thermoeconomic diagnosis to assess and quantify a malfunction effect in terms of additional fuel impact. This study also showed that a malfunction not only causes an increase of resource consumption, but it also causes an increase of residue generation.

The GE90-115B turbofan engine under takeoff conditions and a thrust requirement of $510 \mathrm{kN}$ was taken as a case study. The exergy efficiency of the GE90-115B aircraft engine was $0.36 \%$ with a fuel consumption of $5.86 \mathrm{~kg}_{\mathrm{f}} / \mathrm{s}$ and airflow of $2235.82 \mathrm{~kg}_{\mathrm{a}} / \mathrm{s}$. The total production exergy cost of the aircraft engine was $271.51 \mathrm{MW}$. According to this methodology, the irreversibility and formation costs of the waste heat dissipated from the bypass section and core engine corresponded to $39.78 \%$ and $0.06 \%$, respectively, of the total production exergy cost. The irreversibility and formation costs of the chemical exergy of exhaust gases corresponded to $21.19 \%$ and $2.89 \%$, respectively. Regarding the exergoeconomic cost, $\dot{\Pi}_{P_{T}}=26,754.28 \mathrm{USD} / \mathrm{h}$, of the kinetic exergy produced by the turbofan engine, the methodology was used to determine the contributions of the external resources $(61.04 \%)$, residues $(0.14 \%$ and $33.07 \%$ for waste heat dissipated from the $\mathrm{cS}$ and $\mathrm{hS}$ and $3.28 \%$ for the chemical exergy of the exhaust gases), and capital and operating costs (2.47\%). The malfunction analysis revealed that the performance deterioration of the compressor due to a $10 \%$ reduction in its isentropic efficiency under the same flight conditions and thrust requirement reduced the total kinetic exergy production by $-0.77 \mathrm{MW}$, increased the fuel consumption by $0.49 \mathrm{MW}$, and generated irreversibilities and residues of 0.80 and $0.45 \mathrm{MW}$, respectively. 
Author Contributions: Conceptualization, S.-P.M. and L.-L.R.; data curation, T.-G.E.V.; formal analysis, L.-M.H. and V.-L.J.; investigation, T.-G.E.V.; methodology, L.-M.H., T.-G.E.V., C.-H.S., and L.-L.R.; project administration, L.-L.R.; software, L.-M.H. and T.-G.E.V.; supervision, S.-P.M. and L.-L.R.; validation, L.-M.H. and C.-H.S.; visualization, C.-H.S.; writing, original draft, L.-M.H.; writing, review and editing, S.-P.M., V.-L.J., and L.-L.R. All authors have read and agreed to the published version of the manuscript.

Funding: This research received no external funding.

Acknowledgments: Castro-Hernández S. gratefully acknowledges the scholarship from the Mexican National Council for Science and Technology (CONACyT) to pursue his postgraduate studies.

Conflicts of Interest: The authors declare no conflict of interest.

\section{Abbreviations}

The following abbreviations are used in this manuscript:

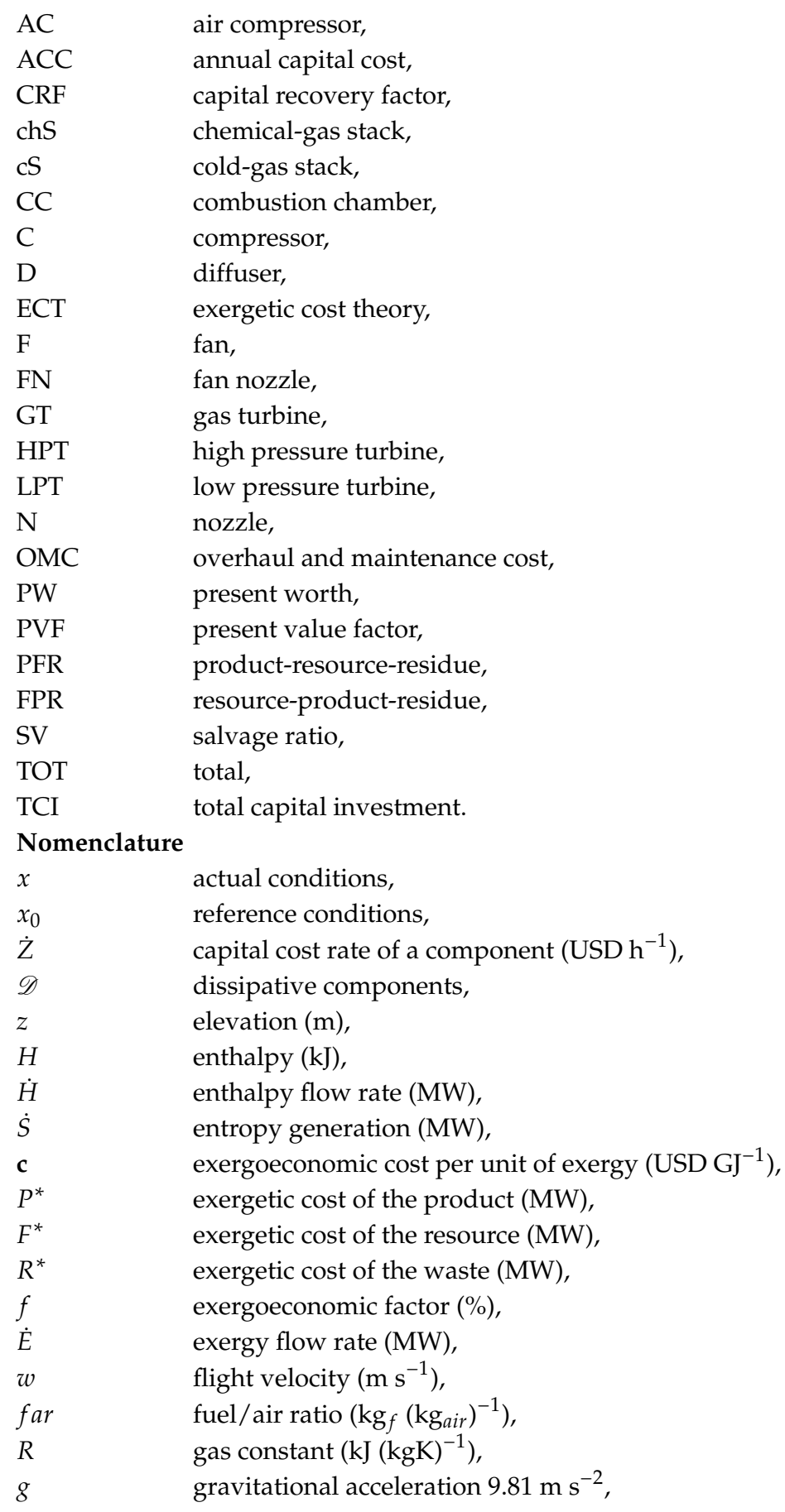


$\dot{Q} \quad$ heat flow rate (MW),

$\dot{I} \quad$ irreversibility flow rate (MW),

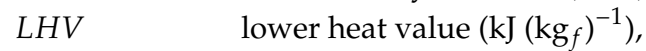

M Mach number (-),

MF malfunction (MW),

$\dot{m} \quad$ mass flow rate $\left(\mathrm{kg} \mathrm{s}^{-1}\right)$,

$x \quad$ molar fraction (-),

$\dot{P} \quad$ product exergy flow (MW),

$P \quad$ pressure (bar),

$\dot{\mathrm{W}}$ power (MW),

$\mathscr{P} \quad$ productive component,

$r \quad$ recirculation coefficient (-),

$\dot{R} \quad$ residue exergy flow (MW),

$\dot{F} \quad$ resource exergy flow (MW),

$q \quad$ specific heat $\left(\mathrm{kJ} \mathrm{kg}^{-1}\right)$,

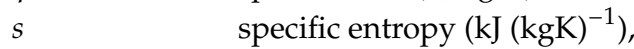

$h$ specific enthalpy $\left(\mathrm{kJ} \mathrm{kg}^{-1}\right)$,

$c_{P} \quad$ specific heat capacity at constant pressure $\left(\mathrm{kJ}(\mathrm{kgK})^{-1}\right)$,

$T$ temperature $\left({ }^{\circ} \mathrm{C}, \mathrm{K}\right)$,

$k \quad$ unit exergoeconomic cost $\left(\mathrm{USD} \mathrm{kJ}^{-1}\right)$,

$k^{*} \quad$ unit exergy cost (-),

$u \quad$ velocity $\left(\mathrm{m} \mathrm{s}^{-1}\right)$,

$V \quad$ volume $\left(\mathrm{m}^{3}\right)$.

Greek symbols

$\beta$

$\mu$

D

$\triangle$

$\eta$

$\lambda$

II

$\xi$

$\varepsilon$

$\pi$

$\mathscr{P}$

$\gamma$

$\kappa$

$\tau$

Subscripts

a

b

$c$

$c g$

$i, j$

D

$k$

$0, e$

$e x$

$e$

$f$

$h$

$S$

$m$

OMC

$P$

bypass ratio (-),

cost ratio for the exhausted gases dissipated in the stack (-),

dissipative component,

drop or increment (\%),

efficiency (\%),

excess of air (\%),

exergoeconomic cost $\left(\mathrm{USD} \mathrm{h}^{-1}\right)$,

exergy grade function (-),

exergy per unit mass $\left(\mathrm{kJ} \mathrm{mol}^{-1}\right)$,

pressure ratio (-),

productive components,

ratio of specific heats (-),

stoichiometric coefficients (-),

thrust (kN).

air,

burner,

cold,

combustion gases,

component,

diagonal,

dissipative component,

environment,

exergetic,

external,

fuel,

hot,

isentropic,

mixture,

overhaul and maintenance,

product, 


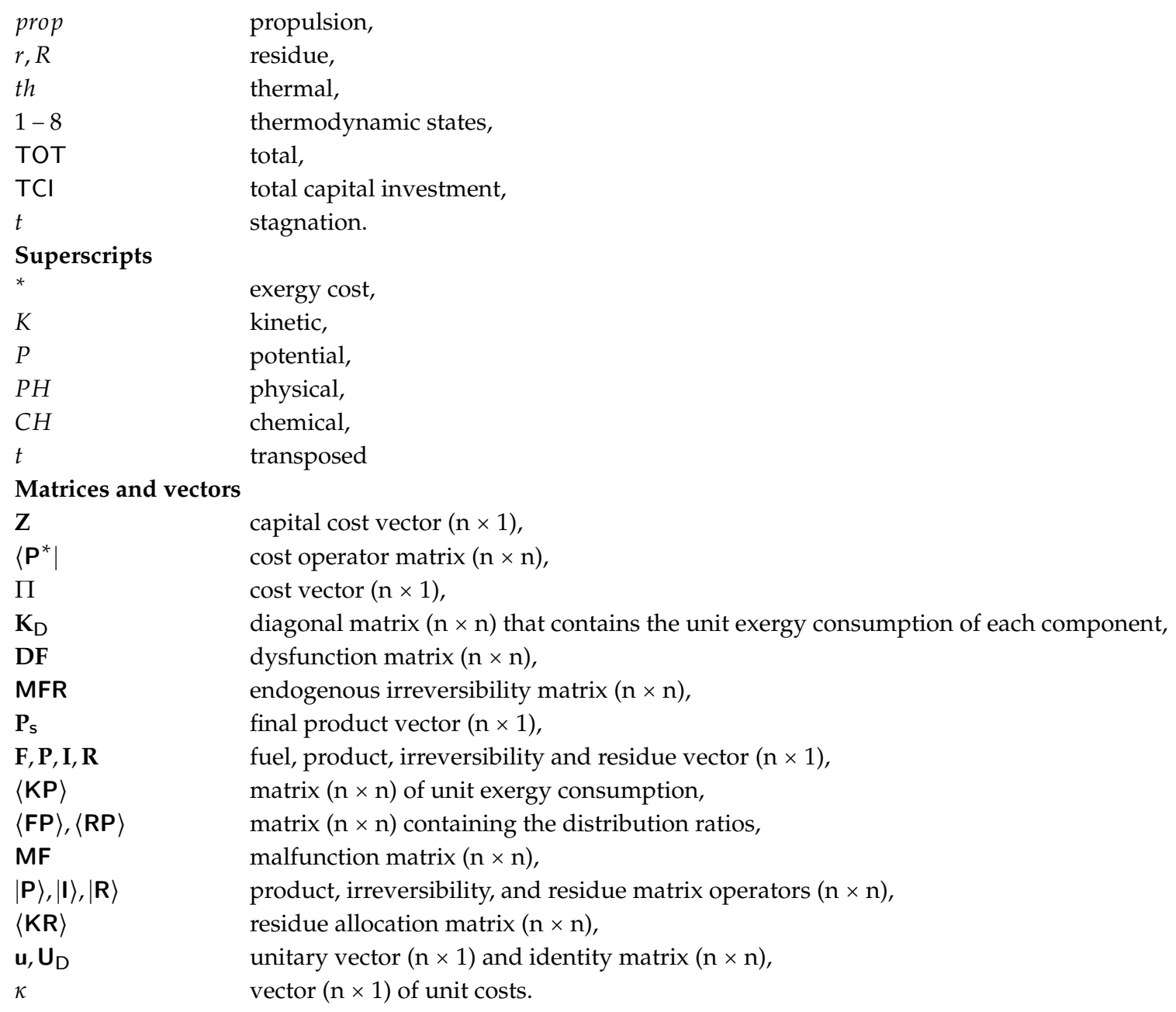

\section{Appendix A. Thermodynamic Properties of the Material and Energy Turbofan Streams}

Table A1 lists the thermodynamic cycle data of the engine under the operating conditions given in Table 5 in the sea level static condition and maximum power setting (i.e., takeoff condition).

Table A1. Thermodynamic states of the turbofan engine under the design operating conditions.

\begin{tabular}{|c|c|c|c|c|c|c|c|c|c|c|}
\hline State & $\begin{array}{c}\dot{m} \\
\left(\mathrm{~kg} \mathrm{~s}^{-1}\right)\end{array}$ & $\begin{array}{c}T \\
(\mathrm{~K})\end{array}$ & $\begin{array}{c}P \\
\text { (bar) }\end{array}$ & $\left(\begin{array}{c}u \\
\left.\mathrm{~m} \mathrm{~s}^{-1}\right)\end{array}\right.$ & $\begin{array}{c}h \\
\left(\mathrm{~kJ} \mathrm{~kg}^{-1}\right)\end{array}$ & $\left(\mathrm{kJ} \mathrm{kg}^{-1} \mathrm{~K}^{-1}\right)$ & $\begin{array}{l}\dot{E}^{P H} \\
(\mathrm{MW})\end{array}$ & $\begin{array}{l}\dot{E}^{C H} \\
(\mathrm{MW})\end{array}$ & $\begin{array}{c}\dot{E}^{K} \\
(\mathrm{MW})\end{array}$ & $\begin{array}{c}\dot{E} \\
(\mathrm{MW})\end{array}$ \\
\hline$f$ & 5.86 & & & & $42,800.00$ & & 45.44 & 0 & 0 & 266.34 \\
\hline$a$ & 2235.82 & 288.15 & 1.01 & 68.02 & 0 & 0.30 & 0 & 13.21 & 5.17 & 18.38 \\
\hline$t a$ & 2235.82 & 290.46 & 1.04 & 0 & 2.31 & 0.30 & 0 & 13.21 & 0 & 18.38 \\
\hline$t 1$ & 2235.82 & 290.46 & 1.04 & 0 & 2.31 & 0.30 & 0 & 13.21 & 0 & 18.28 \\
\hline$t 2$ & 2235.82 & 336.02 & 1.64 & 0 & 48.04 & 0.31 & 0.04 & 13.21 & 0 & 110.79 \\
\hline$t 3$ & 237.85 & 915.29 & 41.62 & 0 & 629.30 & 0.39 & 0.60 & 1.41 & 0 & 144.61 \\
\hline$t 4$ & 243.71 & 1592.00 & 39.53 & 0 & 1633.31 & 1.52 & 1.32 & 9.25 & 0 & 331.20 \\
\hline$t 5$ & 243.71 & 1139.14 & 7.60 & 0 & 1066.02 & 1.58 & 0.74 & 9.25 & 0 & 188.97 \\
\hline t6 & 243.71 & 804.30 & 1.37 & 0 & 646.57 & 1.64 & 0.30 & 9.25 & 0 & 82.58 \\
\hline 7 & 243.71 & 753.49 & 1.01 & 356.78 & 582.92 & 1.64 & 0.24 & 9.25 & 15.51 & 82.27 \\
\hline 8 & 1997.96 & 294.73 & 1.01 & 287.85 & 6.61 & 0.32 & 0 & 11.81 & 82.78 & 94.73 \\
\hline$\dot{W}_{f}$ & 2235.82 & & & & & & 0.05 & 0 & 0 & 102.23 \\
\hline$\dot{W}_{c F}$ & 1997.96 & & & & & & 0.05 & 0 & 0 & 91.35 \\
\hline$\dot{W}_{h F}$ & 237.85 & & & & & & 0.05 & 0 & 0 & 10.88 \\
\hline$\dot{W}_{C}$ & 237.85 & & & & & & 0.58 & 0 & 0 & 138.26 \\
\hline$\dot{W}_{H P T}$ & 243.71 & & & & $248,378.58$ & & 0.57 & 0 & 0 & 138.26 \\
\hline$\dot{W}_{L P T}$ & 243.71 & & & & $248,378.58$ & & 0.42 & 0 & 0 & 102.23 \\
\hline
\end{tabular}




\section{Appendix B. Exergy Balance}

Table A2 presents the resource, product, irreversibility, residue exergy flows, and exergy efficiency of each component, which were calculated by applying the equations of Table 3 .

Table A2. Resources, products, residues, and irreversibilities of the turbofan components $(\dot{F}=\dot{P}+\dot{R}+\dot{I})$.

\begin{tabular}{cccccccc}
\hline Component & $\begin{array}{c}\dot{\boldsymbol{F}} \\
\text { (MW) }\end{array}$ & $\begin{array}{c}\dot{\boldsymbol{P}} \\
(\mathbf{M W})\end{array}$ & $\begin{array}{c}\dot{\boldsymbol{R}} \\
\text { (MW) }\end{array}$ & $\begin{array}{c}\dot{\boldsymbol{I}} \\
(\mathbf{M W})\end{array}$ & $\begin{array}{c}\eta_{\text {ex }} \\
(-)\end{array}$ & $\begin{array}{c}\Delta \dot{\boldsymbol{H}} \\
\text { (MW) }\end{array}$ & $\begin{array}{c}\boldsymbol{T}_{\mathbf{0}} \boldsymbol{\Delta \dot { \boldsymbol { S } }} \\
(\mathbf{M W})\end{array}$ \\
\hline \multicolumn{7}{c}{ Cold-air side (Bypass section) } \\
D & 4.62 & 4.53 & 0 & 0.09 & 0.98 & 4.62 & 0.09 \\
F & 91.35 & 82.67 & 0 & 8.68 & 0.90 & 91.35 & 8.68 \\
FN & 87.05 & 82.78 & 0 & 4.28 & 0.95 & -82.78 & 4.28 \\
cSt & 0.15 & 0.00 & 0.15 & 0.00 & & -13.20 & -13.05 \\
\hline \multicolumn{7}{c}{ Hot-gas side (Core engine) } \\
\hline D & 0.55 & 0.54 & 0 & 0.01 & 0.98 & 0.55 & 0.01 \\
F & 10.88 & 9.84 & 0 & 1.03 & 0.90 & 10.88 & 1.03 \\
C & 138.26 & 132.82 & 0 & 5.43 & 0.96 & 138.26 & 5.43 \\
CC & 266.34 & 186.59 & 0 & 79.75 & 0.70 & 248.38 & 124.71 \\
HPT & 142.23 & 138.26 & 0 & 3.97 & 0.97 & -138.26 & 3.97 \\
LPT & 106.39 & 102.23 & 0 & 4.17 & 0.96 & -102.23 & 4.17 \\
N & 15.82 & 15.51 & 0 & 0.31 & 0.98 & -15.51 & 0.31 \\
hSt & 57.51 & 0.00 & 43.87 & 13.64 & -142.07 & -84.56 \\
chSt & 7.84 & 0.00 & 7.84 & 0.00 & & \\
\hline \multicolumn{7}{c}{ Turbofan Engine } \\
\hline GE90 & 271.51 & 98.29 & 51.86 & 121.37 & 0.36 & 0.00 & 55.08 \\
\hline
\end{tabular}

\section{Appendix C. Exergoeconomic Analysis}

The economic data of the engine were taken from Balli [1]: a total capital investment cost for the engine of $T C I=16,000,000.00$ USD, engine overhaul and maintenance cost of $O M C=800,000.00$ USD, engine operation hours in a year of $\tau=3000 \mathrm{~h}$, interest rate of $i=10 \%$, engine lifetime of $N=30$ years, and engine salvage ratio of $S V=15 \%$. Based on these data, the following economic parameters were estimated: the present value factor $P V F=(1+i)^{-n}=0.05731$, present worth $P W=$ $T C I-S V \cdot P V F=15,862,459.0$ USD, capital recovery factor $C R F=i(1+i)^{n} /\left[(1+i)^{n}-1\right]=0.1061$, annual capital cost $A C C=P W \cdot C R F=682,678.0 \mathrm{USD} /$ year, hourly levelized total capital investment cost rate $\dot{Z}^{T C I}=A C C / \tau=560.893 \mathrm{USD}$, hourly levelized operating and maintenance cost rate of the system $\dot{Z}^{O M C}=O M C / \tau=266.667 \mathrm{USD} / \mathrm{h}$, and total hourly levelized total cost rate of the engine $\dot{\mathrm{Z}}^{\mathrm{TOT}}=\dot{\mathrm{Z}}^{\mathrm{TCI}}+\dot{\mathrm{Z}}^{\mathrm{OMC}}=827.559 \mathrm{USD} / \mathrm{h}$.

In this study, the purchase cost of each productive component was determined from $\dot{Z}_{i}=\omega_{i}^{Z} Z^{T O T}$ with $\omega_{D}^{Z}=5 \%, \omega_{F}^{Z}=17 \%, \omega_{F N}^{Z}=4 \%, \omega_{C}^{Z}=22 \%, \omega_{C C}^{Z}=14 \%, \omega_{H P T}^{Z}=18 \%, \omega_{L P T}^{Z}=12 \%$, and $\omega_{N}^{Z}=8 \%$. The price of the fuel Jet-A1 was considered as $27.04 \mathrm{USD} / \mathrm{GJ}$ [35], and the price for air was taken as zero.

Table A3 presents the cost balance of each component of the GE90-115B turbofan engine.

Columns $f_{r}$ and $f_{Z}$ of Table A3 correspond to the residue and component factors, respectively. They represent the contributions of the residue and component costs, respectively, to the production cost of each component [17]. These indicators are defined as $f_{r, i}=\Pi_{P, i}^{r} / \Pi_{P, i}$ and $f_{Z, i}=\Pi_{P, i}^{Z} / \Pi_{P, i}$, respectively. The exergoeconomic factor $f_{P, i}=\dot{Z}_{i} /\left(\dot{Z}_{i}+c_{F, i} \dot{I}_{i}\right)$ indicates the exergoeconomic costs of a component [17], which is the sum of the component cost $\left(\dot{Z}_{i}\right)$ and the cost of the irreversibilities generated in this component $\left(c_{F, i} \dot{I}_{i}\right)$. If the economic cost of the external resources of the $i$ th component is zero, then $f_{P, i}=1$, as is the case for the D. A low exergoeconomic factor for a component $\left(f_{P, i} \rightarrow\right.$ 0 ) suggests that the cost of the irreversibilities dominates and that the overall cost of the entire system may be reduced by improving the component efficiency (i.e., reducing the exergy destruction), 
even if the capital, operating, and maintenance costs for this component increase [41]. For the turbofan engine, the $\mathrm{CC}$ had a low exergoeconomic factor $\left(f_{P, C C}=0.0147\right.$ or $\left.1.47 \%\right)$; therefore, the component performance could be improved, although this would be limited by the combustion process. An exergoeconomic factor close to unity indicates a low irreversibility cost compared with the component cost; therefore, it is not advisable to attempt to improve the efficiency of the process. In other words, this factor suggests decreasing the investment cost in that component at the expense of its exergetic efficiency [41]. The exergoeconomic indicators of $f_{r}, f_{Z}$, and $f_{p}$ constitute a useful and simple tool for determining possible improvements in an energy system. However, they do not consider the effects induced by changes in the irreversibility of a component on other components.

Table A3. Product exergoeconomic cost decomposition: $\Pi_{P}=\Pi_{P}^{e}+\Pi_{P}^{r}+\Pi_{P}^{Z}$.

\begin{tabular}{|c|c|c|c|c|c|c|c|c|c|c|c|}
\hline & $\dot{\Pi}_{P}$ & $\dot{\Pi}_{P}^{e}$ & $\begin{array}{l}\dot{\Pi}_{P}^{r=h S} \\
\text { (USD/h) }\end{array}$ & $\dot{\Pi}_{P}^{r=c S}$ & $\dot{\Pi}_{P}^{r=c h S}$ & $\dot{\Pi}_{P}^{Z}$ & $f_{r=h S}$ & $f_{r=c}$ & $\begin{array}{c}f_{r=c h S} \\
(\%)\end{array}$ & $f_{Z}$ & $f_{P}$ \\
\hline $\mathrm{D}$ & 42.24 & 0 & 0.80 & 0.06 & 0 & 41.38 & 1.90 & & 0 & & 100 \\
\hline $\mathrm{F}$ & $25,682.73$ & 15,691 & 8569.71 & 41.71 & 842 & 538.15 & 33.50 & 16 & 3.31 & 1.20 & 5.59 \\
\hline $\mathrm{FN}$ & 22,98 & 13,998 & 7645.71 & 37.27 & 751 & 550.10 & 33.44 & 0.16 & 3.31 & 1.38 & 2.85 \\
\hline $\mathrm{C}$ & $40,954.65$ & 20,977 & $18,119.13$ & 3.52 & 1126 & 729.62 & 44.36 & 0.01 & 2.78 & 1.02 & 12.17 \\
\hline $\mathrm{CC}$ & $33,096.83$ & 25,927 & 5663.10 & 0 & 1391 & 115.86 & 17.11 & 0.00 & 4.20 & 0.20 & 1.47 \\
\hline $\mathrm{HPT}$ & $33,457.49$ & 20,977 & $10,804.03$ & 3.52 & 1126 & 547.56 & 32.36 & 0.01 & 3.39 & 0.94 & 13.80 \\
\hline LPT & $25,014.96$ & 15,691 & 8081.70 & 2.63 & 842 & 397.47 & 32.36 & 0.01 & 3.39 & 0.91 & 9.24 \\
\hline $\mathrm{N}$ & 3772.04 & 2334 & 1202.03 & 0.39 & 125 & 110.55 & 32.11 & 0.01 & 3.36 & 1.69 & 47.48 \\
\hline E90 & $26,754.28$ & ,331.89 & 8847.75 & 37.66 & 876.32 & 660.65 & 33.07 & 0.14 & 3.28 & 2.47 & 30.69 \\
\hline
\end{tabular}

\section{Appendix D. Equations of FPR and PFR Symbolic Representations}

Table A4. FPR and PFR symbolic representations (adapted from [13,17,42]).

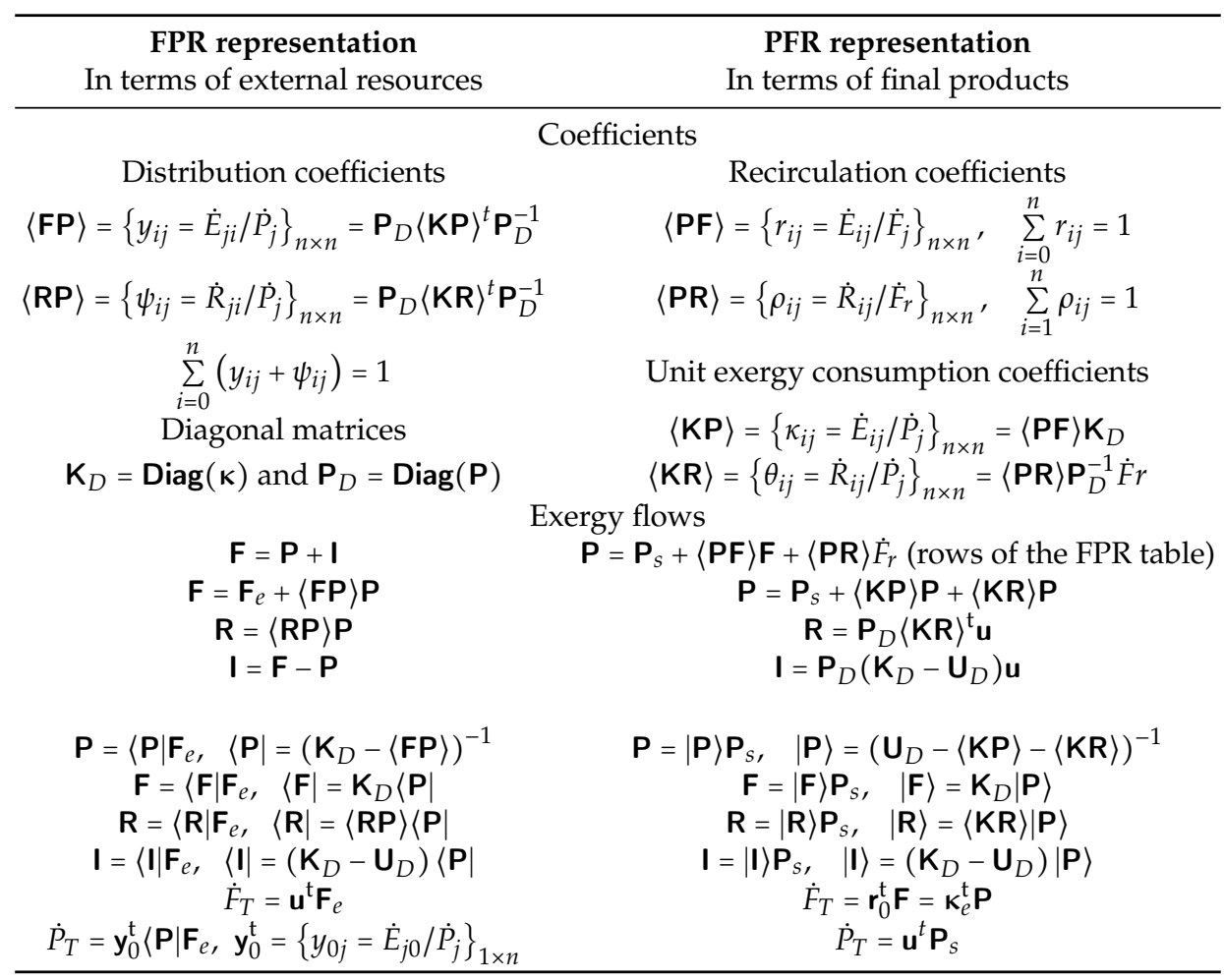


Table A4. Cont.

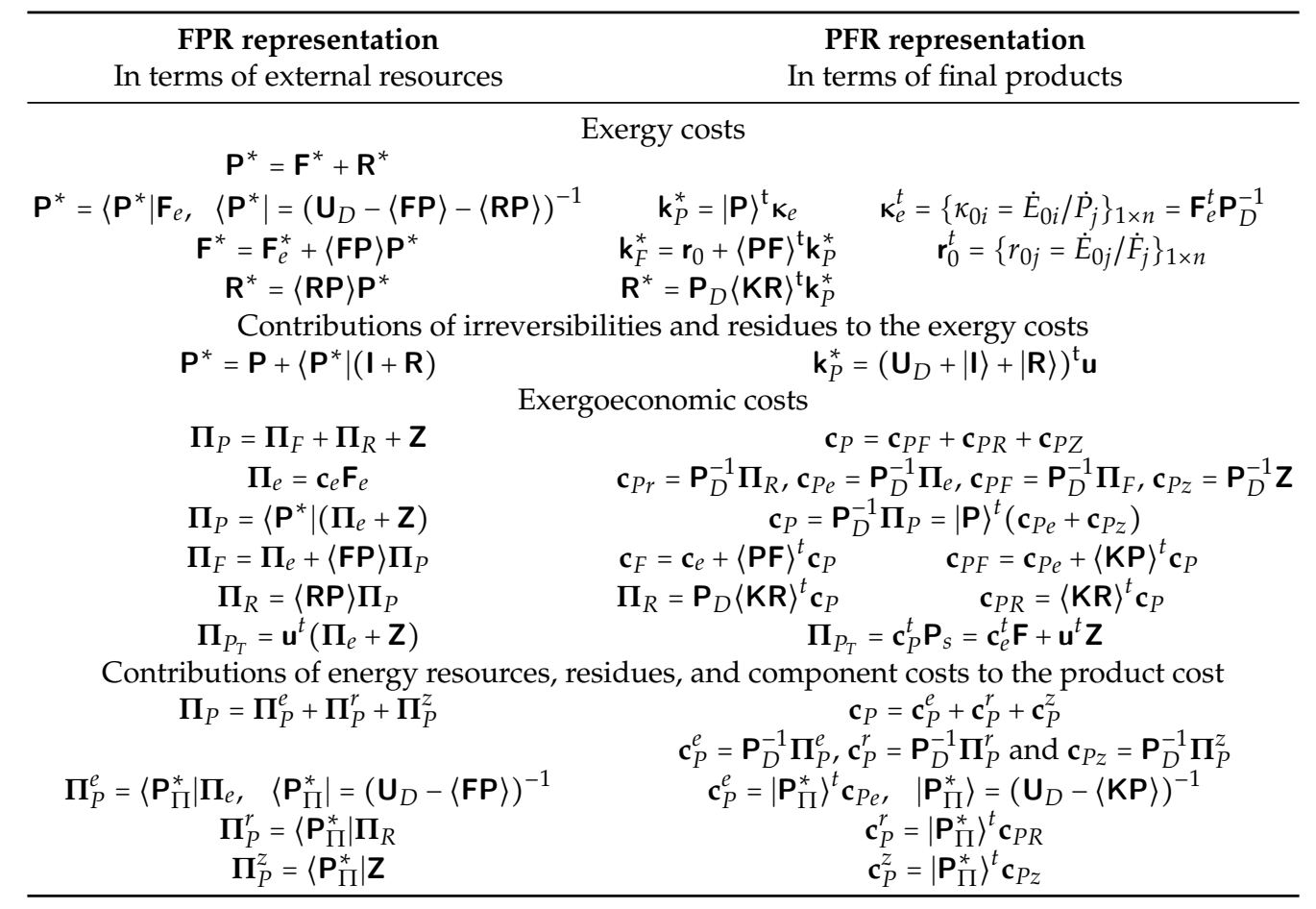

\section{References}

1. Balli, O. Thermodynamic, thermoeconomic and environmental performance analyses of a high bypass turbofan engine used on commercial aircraft. J. Sci. Sak. Univ. 2019, 23, 453-461. [CrossRef]

2. Balli, O.; Sohret, Y.; Karakic, H. Energetic and exergetic performance evaluation of GE90-115B high bypass turbofan engine for different fuel ussage. In Proceedings of the 7th Global Conference on Global Warming (GCGW-2018), Izmir, Turkey, 24-28 June 2018.

3. Balli, O.; Aras, H.; Aras, N.; Hepbasli, A. Exergetic and exergoeconomic analysis of an Aircraft Jet Engine (AJE). Int. J. Exergy 2008, 5, 567. [CrossRef]

4. Turgut, E.; Karakoc, T.; Hepbasli, A. Exergoeconomic analysis of an aircraft turbofan engine. Int. J. Exergy 2009, 6, 277-294. [CrossRef]

5. Aydin, H.; Turan, O.; Midilli, A.; Karakoc, T. Exergetic and exergo-economic analysis of a turboprop engine: A case study for CT7-9C. Int. J. Exergy 2012, 11, 69-88. [CrossRef]

6. Altuntas, O.; Karakoc, T.; Hepbasli, A. A parametric study of a piston-prop aircraft engine using exergy and exergoeconomic analysis methods. Int. J. Green Energy 2015, 12, 2-14. [CrossRef]

7. Altuntas, O.; Karakoc, T.; Hepbasli, A. Exergoeconomic environmental optimization of piston-prop aircraft engines. Int. J. Green Energy 2015, 12, 41-50. [CrossRef]

8. Sahu, M.; Choudhary, T.; Sanjay, Y. Exergoeconomic Analysis of Air Cooled Turboprop Engine: Air Craft Application. In Proceedings of the SAE 2017 AeroTech Congress \& Exhibition, Fort Worth, TX, USA, 26-28 September 2017; SAE Technical Paper 2017-01-2044.

9. Picallo, A.; Catrini, P.; Piacentino, A.; Sala, J. A novel thermoeconomic analysis under dynamic operating conditions for space heating and cooling systems. Energy 2019, 180, 819-837. [CrossRef]

10. Lozano, M.; Valero, A. Theory of the exergetic cost. Energy 1993, 18, 939-960. [CrossRef]

11. Valero, A.; Cuadra, C. Thermoeconomic Analysis. In Exergy, Energy System Analysis and Optimization-Volume II: Thermoeconomic Analysis Modeling, Simulation and Optimization in Energy Systems; Frangopoulos, C.A., Ed.; EOLSS Publishers: Oxford, UK, 2006; Chapter 2.

12. Torres, C.; Valero, A.; Perez, E. Guidelines to developing software for thermoeconomic analysis of energy systems, part I: The thermoeconomic model. Proc. ECOS 2007, 2007, 435e42.

13. Torres, C.; Valero, A.; Rangel, V.; Zaleta, A. On the cost formation process of the residues. Energy 2008, 33, 144-152. [CrossRef] 
14. Seyyedi, S.; Ajam, H.; Farahat, S. A new approach for optimization of thermal power plant based on the exergoeconomic analysis and structural optimization method: Application to the CGAM problem. Energy Convers. Manag. 2010, 51, 2202-2211. [CrossRef]

15. Agudelo, A.; Valero, A.; Torres, C. Allocation of waste cost in thermoeconomic analysis. Energy 2012, 45, 634-643. [CrossRef]

16. Lugo-Méndez, H.D.; Torres-González, E.V.; Castro-Hernández, S.; Salazar-Pereyra, M.; López-Arenas, T.; Lugo-Leyte, R. An Irreversibility-Based Criterion to Determine the Cost Formation of Residues in a Three-Pressure-Level Combined Cycle. Entropy 2020, 22, 299.

17. Torres, C.; Valero, A. Curso de doctorado (termoeconomía); Departamento de Ingeniería Mecánica, Universidad de Zaragoza: Zaragoza, Spain, 2000.

18. Picallo, A.; Escudero, C.; Flores, I.; Sala, J. Symbolic thermoeconomics in building energy supply systems. Energy Build. 2016, 127, 561-570. [CrossRef]

19. Torres, C.; Valero, A.; Serra, L.; Royo, J. Structural theory and thermoeconomic diagnosis: Part I. On malfunction and dysfunction analysis. Energy Convers. Manag. 2002, 43, 1503-1518. [CrossRef]

20. Sala, L.; Picallo, A. Operational diagnosis of thermal installations in buildings. In Exergy Analysis and Thermoeconomics of Buildings; Butterworth-Heinemann: Oxford, UK, 2020; pp. 721-788. [CrossRef]

21. Mattingly, J.D. Elements of Propulsion: Gas Turbines and Rockets; American Institute of Aeronautics and Astronautics: Reston, VA, USA, 2006.

22. Turan, O. An exergy way to quantify sustainability metrics for a high bypass turbofan engine. Energy 2015, 86, 722-736. [CrossRef]

23. Szargut, J. International progress in second law analysis. Energy 1980, 5, 709-718. [CrossRef]

24. Pal, R. Chemical exergy of ideal and non-ideal gas mixtures and liquid solutions with applications. Int. J. Mech. Eng. Educ. 2019, 47, 44-72. [CrossRef]

25. Turan, Ö. Mach number effect on the thermodynamic efficiencies of a turbojet engines: An UAV application. Ömer Halisdemir Üniversitesi Mühendislik Bilimleri Dergisi 2018, 7, 848-863.

26. McGovern, J. Exergy analysis? A different perspective on energy part 1: The concept of exergy. Proc. Inst. Mech. Eng. Part A J. Power Energy 1990, 204, 253-262. [CrossRef]

27. Valero, A.; Usón, S.; Torres, C.; Valero, A. Application of thermoeconomics to industrial ecology. Entropy 2010, 12, 591-612. [CrossRef]

28. Keshavarzian, S.; Gardumi, F.; Rocco, M.; Colombo, E. Off-Design modeling of natural gas combined cycle power plants: An order reduction by means of thermoeconomic input-output analysis. Entropy 2016, $18,71$. [CrossRef]

29. Piacentino, A. Application of advanced thermodynamics, thermoeconomics and exergy costing to a Multiple Effect Distillation plant: In-depth analysis of cost formation process. Desalination 2015, 371, 88-103. [CrossRef]

30. Usón, S.; Valero, A.; Agudelo, A. Thermoeconomics and industrial symbiosis. Effect of by-product integration in cost assessment. Energy 2012, 45, 43-51. [CrossRef]

31. Villalón, J.; Torrent, J.; Aragón, E. Termoeconomía y Optimización Energética; Fundación Gómez Pardo: Madrid, Spain, 2009.

32. Frangopoulos, C.A. Thermo-economic functional analysis and optimization. Energy 1987, $12,563-571$. [CrossRef]

33. Lozano, M.; Valero, A. Thermoeconomic analysis of gas turbine cogeneration systems. In Proceedings of the 1993 ASME Winter Annual Meeting, New Orleans, LA, USA, 28 November-3 December 1993; pp. 311-320. [CrossRef]

34. Stanek, W. (Ed.) Thermodynamics for Sustainable Management of Natural Resources; Springer: Berlin/Heidelberg, Germany, 2017.

35. Dogonchi, A.; Seyyedi, S. Two New Alternative Options for Residues Cost Distribution Ratio. J. Appl. Dyn. Syst. Control 2018, 1, 28-36.

36. Hernández, V.; Capilla, A.; Carlos, L.; Uson, C. Thermoeconomic Diagnosis of Large Industrial Boilers: Microscopic Representation of the Exergy Cost Theory. Ph.D. Thesis, Department of Mechanical Engineering, University of Zaragoza, Zaragoza, Spain, 2005. 
37. Valero, A.; Correas, L.; Zaleta, A.; Lazzaretto, A.; Verda, V.; Reini, M.; Rangel, V. On the thermoeconomic approach to the diagnosis of energy system malfunctions: Part 2. Malfunction definitions and assessment. Energy 2004, 29, 1889-1907. [CrossRef]

38. Kelly, S.; Tsatsaronis, G.; Morosuk, T. Advanced exergetic analysis: Approaches for splitting the exergy destruction into endogenous and exogenous parts. Energy 2009, 34, 384-391. [CrossRef]

39. Valero, A.; Lerch, F.; Serra, L.; Royo, J. Structural theory and thermoeconomic diagnosis: Part II: Application to an actual power plant. Energy Convers. Manag. 2002, 43, 1519-1535. [CrossRef]

40. Cantwell, B. The GE90-An Introduction. In Ed: Stanford Course Material; Stanford University: Stanford, CA, USA, 2011. Available online: https: / /www.google.com.hk/url?sa=t\&rct=j\&q=\&esrc=s\&source=web\& $\mathrm{cd}=\& v e d=2$ ahUKEwilv7e179btAhUWPXAKHSNUBN0QFjAAegQIAhAC\&url=https\%3A\%2F\%2Fwww. kimerius.com\%2Fapp\%2Fdownload\%2F5781574315\%2FThe\%2BGE90\%2B-\%2BAn\%2Bintroduction.pdf\& usg=AOvVaw0DT9tyNfSM9D6iBPQzEvuO (accessed on 26 November 2020).

41. Misra, R.; Sahoo, P.; Sahoo, S.; Gupta, A. Thermoeconomic optimization of a single effect water/LiBr vapour absorption refrigeration system. Int. J. Refrig. 2003, 26, 158-169. [CrossRef]

42. Sala, L.; Picallo, A. Symbolic Thermoeconomics applied to thermal facilities. In Exergy Analysis and Thermoeconomics of Buildings; Butterworth-Heinemann: Oxford, UK, 2020; pp. 663-720. [CrossRef]

Publisher's Note: MDPI stays neutral with regard to jurisdictional claims in published maps and institutional affiliations.

(C) 2020 by the authors. Licensee MDPI, Basel, Switzerland. This article is an open access article distributed under the terms and conditions of the Creative Commons Attribution (CC BY) license (http:/ / creativecommons.org/licenses/by/4.0/). 